\section{Weaning from mechanical ventilation}

\author{
J-M. Boles*, J. Bion\#, A. Connors ${ }^{\ddagger}$, M. Herridge ${ }^{+}$, B. Marsh ${ }^{\S}$, C. Melot ${ }^{f}$, R. Pearl**, \\ H. Silverman ${ }^{\# \#, ~ M . ~ S t a n c h i n a ~}{ }^{\uparrow \uparrow}$, A. Vieillard-Baron ${ }^{++}$, T. Welte ${ }^{\S \S}$
}

Statement of the Sixth International Consensus Conference on Intensive Care Medicine

Organised jointly by the European Respiratory Society (ERS), the American Thoracic Society (ATS), the European Society of Intensive Care Medicine (ESICM), the Society of Critical Care Medicine (SCCM) and the Société de Réanimation de Langue Française (SRLF), and approved by the ERS Executive Committee, February 2007

ABSTRACT: Weaning covers the entire process of liberating the patient from mechanical support and from the endotracheal tube. Many controversial questions remain concerning the best methods for conducting this process. An International Consensus Conference was held in April 2005 to provide recommendations regarding the management of this process. An 11-member international jury answered five pre-defined questions. 1) What is known about the epidemiology of weaning problems? 2) What is the pathophysiology of weaning failure? 3) What is the usual process of initial weaning from the ventilator? 4) Is there a role for different ventilator modes in more difficult weaning? 5) How should patients with prolonged weaning failure be managed?

The main recommendations were as follows. 1) Patients should be categorised into three groups based on the difficulty and duration of the weaning process. 2) Weaning should be considered as early as possible. 3) A spontaneous breathing trial is the major diagnostic test to determine whether patients can be successfully extubated. 4) The initial trial should last $30 \mathrm{~min}$ and consist of either T-tube breathing or low levels of pressure support. 5) Pressure support or assist-control ventilation modes should be favoured in patients failing an initial trial/trials. 6) Noninvasive ventilation techniques should be considered in selected patients to shorten the duration of intubation but should not be routinely used as a tool for extubation failure.

KEYWORDS: Mechanical ventilation, weaning from mechanical ventilation

W eaning from mechanical ventilation is an essential and universal element in the care of critically ill intubated patients receiving mechanical ventilation. Weaning covers the entire process of liberating the patient from mechanical support and from the endotracheal tube, including relevant aspects of terminal care. There is uncertainty about the best methods for conducting this process, which will generally require the cooperation of the patient during the phase of recovery from critical illness. This makes weaning an important clinical issue for patients and clinicians. Immediate, uncomplicated postoperative extubation is excluded from the scope of the current statement.

\section{CONSENSUS ORGANISATION}

In April 2005, a two-day International Consensus Conference in Intensive Care Medicine sponsored by five scientific societies was held in Budapest, Hungary, on the subject of weaning from mechanical ventilation. International Consensus Conferences in Intensive Care Medicine were first introduced in Europe in the early 1990s [1] and were extended to North America in the mid-1990s. The methods of such conferences were specified by the National Institutes of Health [2].

The organisational process was as follows. The International Consensus Liaison Group (ICLG) representing the five sponsoring societies desig-

STATEMENT OF INTEREST: Statements of interest for J. Bion, A. Connors, M. Herridge, R. Pearl, H. Silverman, M. Stanchina and T. Welte can be found at www.erj.ersjournals.com/misc/statements.shtml

AFFILIATIONS

*Dept of Medical Intensive Care and Medical Emergencies, Hôpital de la Cavale Blanche University Hospital, Université de Bretagne Occidentale, Brest

${ }^{++}$Medical Intensive Care Unit, Ambroise Paré University Hospital, Assistance Publique Hôpitaux de Paris, Boulogne, France. \#Dept of Anaesthesia and Intensive Care Medicine, Queen Elizabeth Hospital, Birmingham, UK 'Case Dept of Medicine at MetroHealth Medical Center, Case Western Reserve University, Cleveland, $\mathrm{OH}$,

**Dept of Anaesthesia, Stanford University School of Medicine, Stanford, CA,

\#\#Dept of Medicine, University of Maryland Medical Center, Baltimore, MD

"Dept of Pulmonary and Critical Care Medicine, Rhode Island Hospital, Providence, RI, USA. +Dept of Medicine, Toronto General Hospital, Toronto, ON, Canada. ${ }^{\S}$ Dept of Anaesthesia and Intensive Care Medicine, Trinity College Dublin, Ireland,

${ }^{f}$ Dept of Intensive Care, Erasme Hospital, Free University of Brussels, Brussels, Belgium.

${ }^{\S}$ Dept of Pulmonary Medicine University of Hannover Medical School, Hannover, Germany.

\section{CORRESPONDENCE}

J-M. Boles, Service de Réanimation Médicale et Urgences Médicales,

Hôpital de la Cavale Blanche, CHU, Bd Tanguy Prigent, 29609 Brest cedex, France. Fax: 33298347965

E-mail: jean-michel.boles@

chu-brest.fr

Received:

January 232006

Accepted after revision:

December 222006

European Respiratory Journal

Print ISSN 0903-1936

Online ISSN 1399-3003 
nated the two chairs of the International Consensus Committee (ICC) in charge of the conference. They proposed, in turn, two recognised experts in the field to serve as scientific advisors. All four were responsible for: 1) establishing the five questions to be answered by the jury; 2) selecting the topics and the international experts who were asked to deliver lectures at the conference itself; and 3) selecting the chair and the 10-member international jury. The ICLG ultimately approved the whole process. The experts delivered their presentations during the 2day conference, which was attended by the jury and $\sim 130$ participants. Debate and discussion followed each presentation. The names of the ICC chairs, the scientific advisors and the scientific experts are listed in the Acknowledgements.

\section{CONSENSUS DEVELOPMENT}

The jury held sessions during the 2 days following the Conference, developing and writing a draft of their consensus statement, which was also partially discussed with one of the scientific advisors. The process of consensus formation involved informal discussions during the 2-day sessions. One inconclusive discussion regarding classification of weaning groups required resolution via a formal vote. The jury had unrestricted access to Medline for consulting the literature during its deliberations.

Accordingly, the consensus statement presented hereafter represents the jury's analysis of the experts' oral and written presentations and the relevant literature. Although the jury did not apply a formal evidence-based review of the material available, it followed the general methods of this extensively used consensus process. Subsequently, the consensus statement was finalised through e-mail discussions among members of the jury. The consensus statement includes the jury's opinion on ongoing debates, uncertainties and recommendations for clinical practice and further research.

The consensus statement was approved by the board of administrators of the five organising societies and submitted for peer review by the lead organisation's journal.

\section{THE JURY ANSWERED THE FOLLOWING FIVE SPECIFIC QUESTIONS}

1) What is known about the epidemiology of weaning problems? 2) What is the pathophysiology of weaning failure? 3) What is the usual process of initial weaning from the ventilator? 4) Is there a role for different ventilator modes in more difficult weaning? 5) How should patients with prolonged weaning failure be managed?

\section{QUESTION 1: WHAT IS KNOWN ABOUT THE EPIDEMIOLOGY OF WEANING PROBLEMS? Weaning process}

As illustrated in figure 1, TOBIN [3] proposed at this conference a series of stages in the process of care, from intubation and initiation of mechanical ventilation through initiation of the weaning effort to the ultimate liberation from mechanical ventilation and successful extubation. These six stages are defined in table 1 and are as follows: 1) treatment of acute respiratory failure (ARF); 2) suspicion that weaning may be possible; 3) assessment of readiness to wean; 4) spontaneous breathing trial (SBT); 5) extubation; and possibly 6) reintubation. It is important to recognise that delay in reaching stage 2,

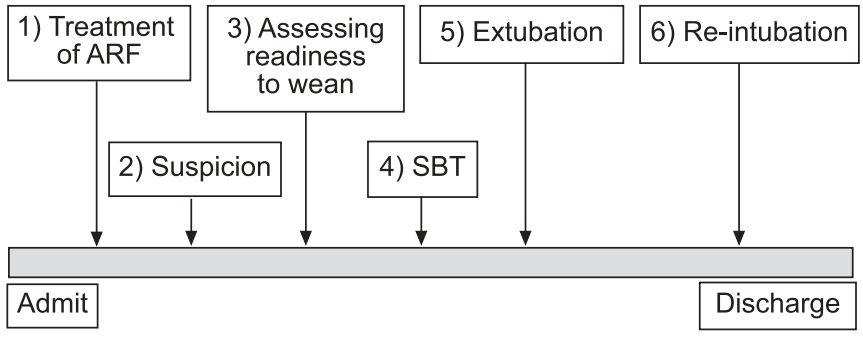

FIGURE 1. Schematic representation of the different stages occurring in a mechanically ventilated patient. ARF: acute respiratory failure; SBT: spontaneous breathing test.

the suspicion that weaning may be possible, and beginning stage 3, assessing readiness to wean, is a common cause of delayed weaning. Stage 2 begins when the clinician first thinks there is a reasonable probability of weaning success. Stage 3 begins when the clinician actually initiates a process of daily tests of readiness to wean in order to confirm this suspicion. Stage 3 ends when the results of the daily test cause a reassessment of the probability to a high enough level to justify an SBT. The weaning process begins with the first SBT, defined as a T-tube trial or a low-level pressure support $\left(\leqslant 8 \mathrm{cmH}_{2} \mathrm{O}\right.$; see Question 2).

There is much evidence that weaning tends to be delayed, exposing the patient to unnecessary discomfort and increased risk of complications, and increasing the cost of care. Time spent in the weaning process represents $40-50 \%$ of the total duration of mechanical ventilation [4-7]. ESTEBAN et al. [7] demonstrated that mortality increases with increasing duration of mechanical ventilation, in part because of complications of prolonged mechanical ventilation, especially ventilator-associated pneumonia and airway trauma [8]. Moreover, mechanical ventilation costs $\sim$ US $\$ 2,000$ per day [9]. Subjects receiving prolonged mechanical ventilation account for $6 \%$ of all ventilated patients but consume $37 \%$ of intensive care unit (ICU) resources [10].

The incidence of unplanned extubation ranges $0.3-16 \%$ [11]. In most cases $(83 \%)$, the unplanned extubation is initiated by the patient, while $17 \%$ are accidental [11]. Almost half of patients with self-extubation during the weaning period do not require reintubation [12], suggesting that many patients are maintained on mechanical ventilation longer than is necessary. Increase in the extubation delay between readiness day and effective extubation significantly increases mortality. In the study by Coplin et al. [13], mortality was $12 \%$ if there was no delay in extubation and $27 \%$ when extubation was delayed. Thus, criteria for readiness to begin weaning (see Question 3) should be systematically evaluated each day to allow prompt initiation of weaning as soon as the patient is ready [14]. This will shorten the weaning process and minimise time on mechanical ventilation [5]. This is also an independent predictor of successful extubation and survival [15].

\section{Definitions of weaning success and failure}

In most studies, weaning failure is defined as either the failure of SBT or the need for reintubation within $48 \mathrm{~h}$ following extubation [16, 17]. Failure of SBT is defined by: 1) objective indices of failure, such as tachypnoea, tachycardia, hypertension, hypotension, hypoxaemia or acidosis, arrhythmia; and 2) 
TABLE 1 Definition of the different stages, from initiation to mechanical ventilation to weaning

\begin{tabular}{ll} 
Stages & Definitions \\
\hline $\begin{array}{l}\text { Treatment of ARF } \\
\text { Suspicion }\end{array}$ & $\begin{array}{c}\text { Period of care and resolution of the disorder that caused respiratory failure and prompted mechanical } \\
\text { ventilation } \\
\text { The point at which the clinician suspects the patient may be ready to begin the weaning process } \\
\text { Assessing readiness to wean }\end{array}$ \\
$\begin{array}{l}\text { Daily testing of physiological measures of readiness for weaning (MIP, fR/ } V \text { T) to determine probability of } \\
\text { weaning success } \\
\text { Extubation } \\
\text { Reintubation }\end{array}$ & $\begin{array}{l}\text { Assessment of the patient's ability to breathe spontaneously } \\
\text { Removal of the endotracheal tube }\end{array}$ \\
\hline
\end{tabular}

ARF: acute respiratory failure, MIP: maximal inspiratory pressure, $\mathrm{fR} / \mathrm{VT}$ : respiratory frequency to tidal volume ratio (rapid shallow breathing index)

subjective indices, such as agitation or distress, depressed mental status, diaphoresis and evidence of increasing effort (see Question 3) [5, 16-18]. Failure of a SBT is often related to cardiovascular dysfunction or inability of the respiratory pump to support the load of breathing. Extubation failure may be related to the same causes $[19,20]$, in addition to upper airway obstruction or excessive secretions [11].

Failure of extubation is associated with high mortality rate, either by selecting for high-risk patients or by inducing deleterious effects such as aspiration, atelectasis and pneumonia [21]. Interestingly, mortality is not especially increased when failure of extubation is related to upper airway obstruction (one out of nine patients; $11 \%$ ) but is markedly increased in the other cases (19 out of 52 patients; 36\%) [22]. Predictors of extubation failure have been reported [23], such as excess secretions, arterial carbon dioxide tension $\left(\mathrm{Pa}_{1} \mathrm{CO}_{2}\right)>5.99 \mathrm{kPa}(45 \mathrm{mmHg})$, duration of mechanical ventilation $>72 \mathrm{~h}$, upper airway disorders and a prior failed weaning attempt.

Rate of weaning failure after a single SBT is reported to be 26$42 \%$ (table 2 ) $[17,22]$. This variation in the rate of weaning failure among the studies may be due to differences in the definition of weaning failure, especially differences in the subjective indexes used to define failed SBT, or variation in the patients studied. For instance, chronic obstructive pulmonary disease (COPD) appears as an independent risk factor for increased duration of weaning and weaning failure [18]. VALLVERDU et al. [17] reported that weaning failure occurred in as many as $61 \%$ of COPD patients, in $41 \%$ of neurological patients and in $38 \%$ of hypoxaemic patients. Contradictory results exist regarding the rate of weaning success among neurological patients [13, 17]. The study by CopLIN et al. [13] of brain-injured patients demonstrated that $80 \%$ of patients with a Glasgow coma score $<8$ and $91 \%$ of patients with a Glasgow coma score $<4$ were successfully extubated. Finally, as shown in table 2, in 2,486 patients from six randomised studies, 524 patients failed SBT and 252 failed extubation after passing SBT, leading to a total weaning failure rate of $31.2 \%$. [16-18, 22, 24, 25].

Several studies have recently proposed the use of noninvasive ventilation (NIV) for extubated patients in different clinical situations, including prophylactic intervention in COPD patients who failed SBT [26], patients with repeated SBT failure [27] and post-surgical patients. However, the effectiveness of NIV remains to be determined.

The increased use of NIV raises the question of how to define weaning success or failure. The current authors propose the following definitions. Weaning success is defined as extubation and the absence of ventilatory support $48 \mathrm{~h}$ following the extubation. Weaning failure is defined as one of the following: 1) failed SBT; 2) reintubation and/or resumption of ventilatory support following successful extubation; or 3) death within $48 \mathrm{~h}$ following extubation.

Since NIV may allow extubation while mechanical ventilation is continued in the form of NIV, an intermediate category

\begin{tabular}{|c|c|c|c|c|c|c|c|}
\hline First author [Ref.] & Yr & Subjects & $\begin{array}{c}\text { Failed initial } \\
\text { SBT }\end{array}$ & $\begin{array}{c}\text { Passed Initial } \\
\text { SBT }\end{array}$ & Re-intubated & $\begin{array}{c}\text { Total failed } \\
\text { weaning }\end{array}$ & $\begin{array}{c}\text { Successful } \\
\text { weaning }\end{array}$ \\
\hline FARIAS [24] & 2001 & 257 & $56(22)$ & 201 & $28(14)$ & $84(32.7)$ & 173 \\
\hline EstebAN [22] & 1999 & 526 & $73(14)$ & 453 & $61(13)$ & $134(25.5)$ & 392 \\
\hline EstebAN [25] & 1997 & 484 & $87(18)$ & 397 & $74(19)$ & 161 (33.3) & 323 \\
\hline EstebAN [16] & 1995 & 546 & $130(24)$ & 416 & $58(14)$ & $188(34.4)$ & 358 \\
\hline BROCHARD [18] & 1994 & 456 & $109(24)$ & 347 & $8(3)$ & $117(25.6)$ & 339 \\
\hline Total & & 2486 & $524 / 2486(21 \%)$ & $1962 / 2486$ (79\%) & $252 / 1962(13 \%)$ & $776(31.2 \%)$ & $1710 / 2486(68.8 \%)$ \\
\hline
\end{tabular}

Data are presented as $n$ or $n(\%)$, unless otherwise stated. SBT: spontaneous breathing trial 


\begin{tabular}{l}
$\begin{array}{l}\text { TABLE } 3 \text { Classification of patients according to the weaning process } \\
\text { Group/category }\end{array}$ \\
$\begin{array}{l}\text { Definition } \\
\text { Patients who proceed from initiation of weaning to successful extubation on the first } \\
\text { attempt without difficulty } \\
\text { Patients who fail initial weaning and require up to three SBT or as long as } 7 \text { days } \\
\text { from the first SBT to achieve successful weaning }\end{array}$ \\
$\begin{array}{l}\text { Difficult weaning } \\
\text { Prolonts who fail at least three weaning attempts or require }>7 \text { days of weaning } \\
\text { after the first SBT }\end{array}$ \\
\hline SBT: spontaneous breathing trial.
\end{tabular}

called "weaning in progress" is recommended for patients who are extubated but remain supported by NIV.

\section{Classification of patients}

A new classification of patients into three groups is proposed, as suggested by BROCHARD [28] during the International Concensus Conference, according to the difficulty and length of the weaning process (table 3 ).

The simple weaning group includes patients who successfully pass the initial SBT and are successfully extubated on the first attempt. This group, named group 1, represents $\sim 69 \%$ of weaning patients (table 2). Prognosis in this group is good, with an ICU mortality of $\sim 5 \%[17,22]$ and an in-hospital mortality of $\sim 12 \%$ [22]. The remaining patients $(\sim 31 \%)$ represent groups 2 and 3 . In this population, ICU mortality is $\sim 25 \%[17,22]$.

Group 2, difficult weaning, includes patients who require up to three SBT or as long as 7 days from the first SBT to achieve successful weaning.

Group 3, prolonged weaning, includes patients who require more than three SBT or $>7$ days of weaning after the first SBT. Indeed, in the study by ESTEBAN et al. [22], the 75th percentile for duration of weaning for all patients, for those with COPD and those with acute respiratory distress syndrome (ARDS) was 4,5 and 6 days, respectively. Moreover, estimating from the survival curves from the studies by EsTEBAN et al. [16] and BROCHARD et al. [18], about half of the patients who failed initial SBT (group 2) still required mechanical ventilation at day 7.

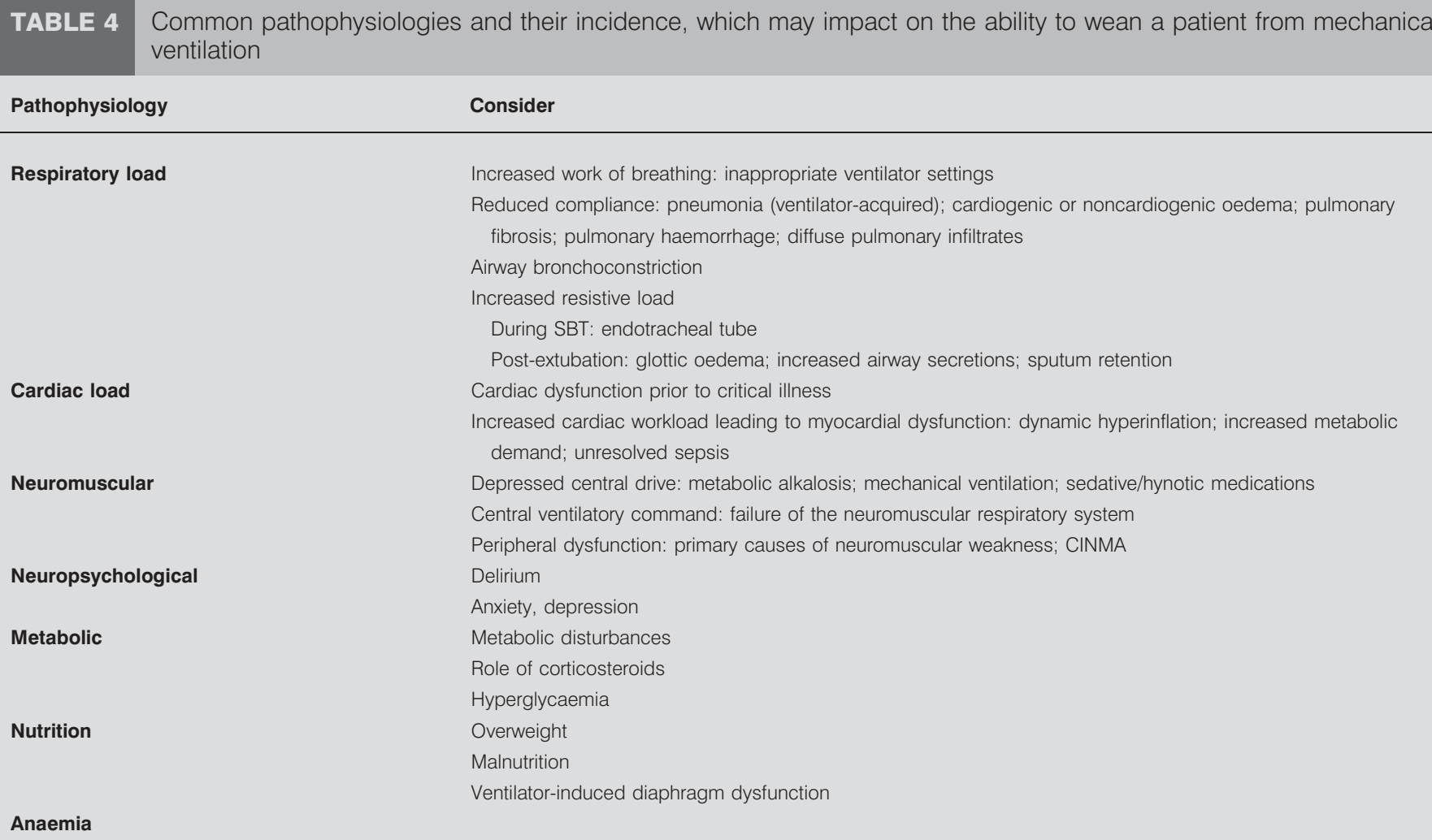

Pathophysiology

Respiratory load

Cardiac load

Neuromuscular

Neuropsychological

Metabolic

Nutrition

Consider

Increased work of breathing: inappropriate ventilator settings

Reduced compliance: pneumonia (ventilator-acquired); cardiogenic or noncardiogenic oedema; pulmonary

fibrosis; pulmonary haemorrhage; diffuse pulmonary infiltrates

Airway bronchoconstriction

Increased resistive load

During SBT: endotracheal tube

Post-extubation: glottic oedema; increased airway secretions; sputum retention

Cardiac dysfunction prior to critical illness

Increased cardiac workload leading to myocardial dysfunction: dynamic hyperinflation; increased metabolic demand; unresolved sepsis

Depressed central drive: metabolic alkalosis; mechanical ventilation; sedative/hynotic medications

Central ventilatory command: failure of the neuromuscular respiratory system

Peripheral dysfunction: primary causes of neuromuscular weakness; CINMA

Delirium

Anxiety, depression

Metabolic disturbances

Role of corticosteroids

Hyperglycaemia

Overweight

Malnutrition

Ventilator-induced diaphragm dysfunction 
Therefore, the current authors estimate that $\sim 15 \%$ of patients would be in the prolonged weaning group (group 3).

\section{Recommendations}

Patients can be readily categorised into three groups based on the difficulty and duration of the weaning process. Clear definitions of the timing, stages and outcomes of the weaning process will support further research in weaning. Clinicians should evaluate readiness for weaning early in the hospital course to allow prompt initiation of the weaning process. An efficient weaning process reduces time on the ventilator and improves patient outcomes.

\section{Further research}

Further study is needed of the effectiveness of NIV in the process and outcomes of weaning. The proposed definitions of the weaning process and the groups of patients who undergo weaning need to receive careful testing and scrutiny. Studies of the patients' outcomes in the difficult weaning and prolonged weaning groups are needed.

\section{QUESTION 2: WHAT IS THE PATHOPHYSIOLOGY OF WEANING FAILURE?}

A thorough and systematic search for potentially reversible pathologies should be conducted in all patients who did not fulfil simple weaning as previously defined. Using the definitions put forth in this statement, this places the patient in group 2, and reversible aetiologies for weaning failure may be categorised as follows: respiratory load, cardiac load, neuromuscular competence (central and peripheral), critical illness neuromuscular abnormalities (CINMA), neuropsychological factors, and metabolic and endocrine disorders (table 4). These same factors should be sought in group 3 patients, who have required mechanical ventilation for $>7$ days. The pathophysiology of weaning failure in group 3 may be complex and multifactorial. Irreversible lesions may become apparent at this time point or clearly delineated issues (e.g. cardiac dysfunction or CINMA) may be difficult to optimise or slow to resolve. In this group of chronically critically ill patients it is imperative that there is a disciplined approach to ongoing surveillance for any reversible or remediable factors.

\section{Respiratory load}

The decision to attempt discontinuation of mechanical ventilation has largely been based on the clinician's assessment that the patient is haemodynamically stable, awake, the disease process has been treated adequately and that indices of minimal ventilator dependency are present (e.g. inspiratory oxygen fraction $\left(F \mathrm{I}, \mathrm{O}_{2}\right) \leqslant 0.5$, positive end-expiratory pressure (PEEP) $\leqslant 8 \mathrm{cmH}_{2} \mathrm{O}$, arterial oxygen tension $\left(\mathrm{Pa}_{1} \mathrm{O}_{2}\right) / F \mathrm{I}, \mathrm{O}_{2}>20.0 \mathrm{kPa}$ $(150 \mathrm{mmHg})$, arterial oxygen saturation $\geqslant 90 \%)$. The success of weaning will be dependent on the ability of the respiratory muscle pump to tolerate the load placed upon it. This respiratory load is a function of the resistance and compliance of the ventilator pump. Normal respiratory system resistance is $<5 \mathrm{cmH}_{2} \mathrm{O} \cdot \mathrm{L}^{-1} \cdot \mathrm{s}^{-1}$. Normal respiratory system static compliance is $0.06-0.1 \mathrm{~L} \cdot \mathrm{cmH}_{2} \mathrm{O}^{-1}$. Improvement in static lung compliance may alert the clinician to the potential for weaning from mechanical ventilation and has been incorporated into a computer-driven model [29] where a plateau pressure of $\leqslant 30 \mathrm{cmH}_{2} \mathrm{O}$ for a tidal volume $(V \mathrm{~T}) \geqslant 8 \mathrm{~mL} \cdot \mathrm{kg}^{-1}$ is included in the algorithm prior to decreasing levels of pressure support ventilation (PSV). Maximum inspiratory pressure has been used to assess inspiratory muscle strength, measured either after negative pressure is maintained for $1 \mathrm{~s}$ after a forceful expiration to residual volume or using a unidirectional expiratory valve. A maximum inspiratory pressure value of $\leqslant-20--25 \mathrm{cmH}_{2} \mathrm{O}$ has been referenced as a predictive index for successful weaning [30, 31].

An excess work of breathing (WOB) may be imposed by inappropriate ventilator settings (e.g. inadequate inspiratory flow rate or flow trigger setting) resulting in ventilator dysynchrony [32]. Components of such dysynchrony include the lead time between onset of inspiratory effort and the onset of flow delivery, respiratory effort after onset of flow, ineffective triggering, expiratory effort prior to switchover from mechanical inflation to exhalation, and the effect of high intrinsic PEEP (representing a threshold load).

Reduced pulmonary compliance may be secondary to pneumonia, cardiogenic or noncardiogenic pulmonary oedema, pulmonary fibrosis, pulmonary haemorrhage or other diseases causing diffuse pulmonary infiltrates. Pneumonia is common in critically ill patients, either as the primary admission diagnosis or as a subsequent ventilator-acquired pneumonia. Ventilator-acquired pneumonia has a variable incidence of 9$67 \%$ [33] and an attributable mortality of up to $50 \%$. Shortening the weaning process is an important goal in reducing the incidence of ventilator-acquired pneumonia [27, 34]. However, adequate treatment of the underlying disease process is a prerequisite to extubation. The need for reintubation is associated with a 4.5-fold increased risk of nosocomial pneumonia [21]. Therapeutic guidelines and recommendations for reducing the incidence of ventilator-acquired pneumonia have been recently published [35]. Reduced pulmonary compliance attributable to cardiogenic or noncardiogenic pulmonary oedema should be considered, with optimisation of cardiac function and clearance of lung water instituted as clinically indicated. Reduced pulmonary compliance secondary to pulmonary fibrosis (acute or pre-morbid) or reduced chest wall compliance secondary to kyphoscoliosis may be less amenable to treatment (more likely to represent group 3 patient profile). The splinting effect of obesity, abdominal distension or ascites may be further considerations.

Additional load may be related to reversible airway bronchoconstriction, which should be addressed prior to SBT. Patients with COPD may also manifest dynamic hyperinflation and reduced compliance when forced to operate at the less efficient upper margin of the pressure-volume curve.

The process of weaning may impose an increased resistive load on the ventilatory muscles, either from the endotracheal tube during an SBT or post-extubation from glottic oedema or increased airway secretions and sputum retention [36-38].

\section{Cardiac load}

Many patients will have identified ischaemic heart disease, valvular heart disease, systolic or diastolic dysfunction prior to, or identified during, their critical illness. More subtle and less easily recognised are those patients with myocardial 
dysfunction, which is only apparent when exposed to the workload of weaning.

The transfer of a patient from positive pressure ventilation to spontaneous ventilation is associated with increased venous return and negative intra-thoracic pressure causing increased left ventricular afterload and increased myocardial oxygen consumption. Thus, latent or unrecognised myocardial dysfunction may become manifest at the commencement of the weaning attempts [39-41]. This is further reflected in the beneficial effects seen with the application of continuous positive airway pressure (CPAP) [42] or NIV in cardiogenic pulmonary oedema [43].

There are several contributors to increased cardiac workload. These include: dynamic hyperinflation (intrinsic PEEP), which increases pulmonary vascular resistance, reduces right ventricular filling and impairs cardiac output; the increased metabolic demand of the weaning process; and unresolved systemic disease (e.g. sepsis). There is an obligatory increase in cardiac output to meet the metabolic demand of a weaning trial. Measurable indices include increased serum lactate and decreased mixed venous oxygen saturation $\left(S \mathrm{~V}, \mathrm{O}_{2}\right)$. Weaning failure has been predicted through the use of $\mathrm{SV}, \mathrm{O}_{2}$ during SBT [44] or measurement of gastric mucosal pH [45]. Myocardial ischaemia may become manifest during SBT. This may result in reduced left ventricular compliance, pulmonary oedema and increased WOB.

\section{Neuromuscular competence}

Liberation from mechanical ventilation requires the resumption of neuromuscular activity to overcome the impedance of the respiratory system, to meet metabolic demands and to maintain carbon dioxide homeostasis. This requires an adequate signal generation in the central nervous system, intact transmission to spinal respiratory motor neurons, respiratory muscles and neuromuscular junctions. Disruption of any portion of this transmission may contribute to weaning failure.

\section{Depressed central drive}

With complete absence of central drive, patients do not exhibit any ventilatory activity upon discontinuation from the ventilator, and this persists despite hypercapnia and hypoxaemia. Examples of this may include, but are not limited to, encephalitis, brainstem haemorrhage/ischaemia and neurosurgical complications. It is more challenging to identify a reduction in ventilatory drive. The carbon dioxide responsiveness test may be used to assess this but there are few studies evaluating its utility in critically ill patients. The responsiveness of central drive to carbon dioxide assessed from the 100-ms occlusion pressure has been shown to predict weaning success in a small case series [46].

Central drive may be impeded by metabolic alkalosis, mechanical ventilation itself or the use of sedative/hypnotic medications. Of these three possible contributors, there are only data that link sedative/hypnotic medication use to prolonged weaning. The importance of the contribution of daily awakening and heightened awareness over sedation to prolonged weaning and ICU stay has been established in the literature [47].
Central ventilatory command

Failure of the neuromuscular respiratory system to maintain homeostasis results in an increased central drive to breathe, which in turn may cause ventilatory failure. This pattern may be observed in response to an increased resistive load from upper airway obstruction, an imbalance between mechanical load and respiratory muscle capacity or isolated muscle weakness. Abnormalities of upper airway motor control are a potential cause of extubation failure [37].

\section{Peripheral dysfunction}

After respiratory or cardiac causes have been excluded in the difficult-to-wean patient, the contribution of peripheral neuromuscular abnormalities should be considered. These neuromuscular disorders may be common and have been reported in up to $62 \%$ of patients in some studies [48]. Primary causes of neuromuscular weakness such as Guillain-Barré syndrome, myasthenia gravis and motor neuron disease are usually apparent before weaning difficulties are encountered. However, occasionally these new diagnoses will be made in the course of investigating the difficult-to-wean patient. Most neuromuscular dysfunction that complicates weaning is acquired during the ICU stay.

\section{Critical illness neuromuscular abnormalities}

CINMA are the most common peripheral neuromuscular disorders encountered in the ICU setting and usually involve both muscle and nerve [49]. These disorders were first described in Canada and France in 1984 [50, 51]. The reported prevalence of CINMA in the literature has varied $50-100 \%$ and this has been associated with severity of illness, multiple organ dysfunction, exposure to corticosteroids, presence of hyperglycaemia and prolonged ICU stay [52-56]. The diagnosis of CINMA may be made at the bedside using the Medical Research Council score [57] with confirmation by electrophysiological testing and muscle biopsy when appropriate. Clinically significant weakness has been associated with a score $<48$ [56]. CINMA presents as a motor deficit where muscle weakness is bilateral, symmetrical and most marked in the proximal muscles. Electroneuromyographic studies of the limbs show sensorimotor axonopathy with preserved velocities and decreased amplitude of compound action potentials. Neuromuscular transmission is normal except in the case of prolonged neuromusuclar blocade. In patients with severe muscle involvement, decreased motor action potentials and fibrillation potentials may resemble a motor axonopathy and a true distinction between a nerve and/or muscle lesion may be difficult. Myopathy may be confirmed on muscle biopsy and type II fibre drop-out with a loss of myosin filaments is a consistent finding [58].

Three studies have shown that diaphragmatic electrophysiological abnormalities are common in patients with locomotor electroneuromyographic abnormalities and were more prevalent when the limb weakness was more severe $[52,59,60]$.

The bedside evaluation of respiratory neuromuscular weakness is difficult. Maximum inspiratory pressure and vital capacity are dependent on patient comprehension and cooperation and are hindered by the endotracheal tube. As a result, many have questioned their ability to detect respiratory neuromuscular dysfunction that contributes to prolonged 
weaning [61-63]. Twitch transdiaphragmatic pressure in response to bilateral stimulation of the phrenic nerves can give an effort-independent measure of diaphragmatic contractility [64]. Clinical applicability is limited as this requires placement of both an oesophageal and gastric balloon. The airway pressure at the end of the tracheal tube in response to phrenic nerve stimulation has been proposed to be a noninvasive alternative measure and may have a role in monitoring inspiratory muscle contractility as its correlation to twitch transdiaphragmatic pressure is weak [64].

The contribution of CINMA to prolonged mechanical ventilation has been studied in 10 cohorts of ICU patients [54, 56, 6572]. Four studies have shown an association between CINMA and an increased duration of weaning or weaning failure $[49,67$, $70,71]$. Two of these used multivariable analysis to control for confounding factors and showed that CINMA was an independent risk factor for duration of mechanical ventilation and weaning failure, including the need for tracheostomy [49, 71].

Neuromuscular dysfunction related to CINMA usually improves over weeks [65] but some disability may persist over months and interfere with activities of daily living [73, 74].

\section{Psychological dysfunction}

\section{Delirium}

Delirium, or acute brain dysfunction, is a disturbance of the level of cognition and arousal and, in ICU patients, has been associated with many modifiable risk factors, including: use of psychoactive drugs; untreated pain; prolonged immobilisation; hypoxaemia; anaemia; sepsis; and sleep deprivation [75]. Important literature regarding delirium in critically ill patients has emerged since 2001. The prevalence of delirium has been reported to range 22-80\% [76, 77]. It is associated with prolonged ICU stay and is a predictor of higher mortality up to 6 months after discharge from the ICU [77]. A delirium screening tool has been developed and validated but there is no established consensus on treatment [75]. Delirium has not yet proven to be directly linked to weaning difficulties but studies are underway.

Anxiety and depression

Many patients suffer significant anxiety during their ICU stay and the process of weaning from mechanical ventilation. These memories of distress may remain for years [78]. The prevalence of anxiety during ICU is reported to be $30-75 \%[79,80]$. Patients report the following as important contributors to anxiety: dyspnoea [81]; inability to communicate [82]; and sleep disruption [78].

Sleep studies have shown that patients are unable to rest or sleep, and 25\% report nightmares [78]. Furthermore, polysomnographic studies show that ICU patients suffer from frequent arousals and sleep fragmentation [83]. Sleep disruption may be related to ventilatory mode [84] and recent evidence suggests that ambient noise in the ICU may not be as significant a contributor as initially thought [85]. Depression may occur as a discrete disorder or in association with ICU delirium [86].

Several strategies have been reported to minimise anxiety during mechanical ventilation. These include: improvement of speech by increasing inspiratory time and PEEP, or ventilating with bi-level PSV [87]; improvement of sleep by minimising noise, light and nursing interventions at night; and the use of relaxation techniques, such as biofeedback. The combination of biofeedback with $V \mathrm{~T}$ technique may reduce anxiety and decrease the time to wean from mechanical ventilation [88].

\section{Metabolic and endocrine}

Metabolic disturbances

Hypophosphataemia, hypomagnesaemia and hypokalaemia all cause muscle weakness. Hypothyroidism and hypoadrenalism may also contribute to difficulty weaning. However, data are not available that specifically evaluate the relative contribution of each of these metabolic derangements to duration of mechanical ventilation weaning failure.

\section{Role of corticosteroids}

The importance of corticosteroids in weaning failure, either their relative deficiency or supplementation, needs further analysis. Physiological replacement of steroids is common in current clinical practice as clinicians target an absolute or relative cortisol deficiency [89]. Data from the Corticus study may help further define the role of steroids for the critically ill patient. In one outcome study of survivors of ARDS [74], the absence of corticosteroids was associated with a better functional outcome. The effect of drug dosage needs further elucidation, with higher doses than those recommended for physiological replacement therapy being associated with severe myopathy [72]. Any exposure to exogenous corticosteroids during the ICU stay might cause muscle weakness and possibly contribute to the duration of mechanical ventilation.

Corticosteroid therapy impairs glycaemic control. Significant reduction in the mean duration of mechanical ventilation has been reported in a population of surgical patients in whom a tight glycaemic control regimen was instituted [90]. Whether this effect is translated to a broader group of medical intensive care patients awaits analysis.

\section{Nutrition}

Overweight

The mechanical effects of obesity (overweight is defined as body mass index $>25 \mathrm{~kg} \cdot \mathrm{m}^{-2}$ ) with decreased respiratory compliance, high closing volume/functional residual capacity ratio and elevated WOB might be expected to impact on the duration of mechanical ventilation. In a secondary analysis of the data for the ARDS Network trials of mechanical ventilation ( 6 versus $12 \mathrm{~mL} \cdot \mathrm{kg}^{-1} V \mathrm{~T}$ ), the duration of mechanical ventilation was similar for overweight and obese patients compared with the normal body weight group $\left(18.5-24.9 \mathrm{~kg} \cdot \mathrm{m}^{-2}\right)$ [91]. Another study looked at the effect of obesity on length of ICU stay, which was increased, but the duration of mechanical ventilation was not [92].

\section{Malnutrition}

Although malnutrition has been reported in as high as $40 \%$ of critically ill patients, data linking it to weaning difficulty are limited. For instance, in the ARDS Network trials, $4.7 \%$ of patients were defined as underweight. Underweight patients, defined as those with a body mass index $<20 \mathrm{~kg} \cdot \mathrm{m}^{-2}$, may suffer depressed ventilatory drive [93], limited muscle mass and weaning difficulty. 


\section{Ventilator-induced diaphragm dysfunction and critical illness oxidative stress}

Ventilator-induced diaphragm dysfunction and critical illness oxidative stress is defined as loss of diaphragm force-generating capacity that is specifically related to use of controlled mechanical ventilation [94]. The pathophysiology comprises muscle atrophy, structural injury, fibre-type transformation and remodelling. In rabbit diaphragm models, after $72 \mathrm{~h}$ of controlled mechanical ventilation mitochondrial swelling, myofibril damage and increased lipid vacuoles are noted [95]. Oxidative stress may play an important role in this process, with oxidative modifications noted within $6 \mathrm{~h}$ of commencing controlled mechanical ventilation [96].

The role of trace element and vitamin supplementations that support antioxidant function in the critically ill patient is evolving. One prospective randomised trial [97] found that $\alpha$-tocopherol and ascorbic acid supplementation reduced length of ICU stay and duration of mechanical ventilation in a surgical ICU, when compared with unsupplemented controls. Such supplementation, particularly selenium, would appear to be safe in critically ill patients [98], though route (enteral versus parenteral) and dosage require further analysis. It is proposed that this may help attenuate ventilator-induced diaphragmatic dysfunction [94]. Genetic susceptibility to oxidative stress remains unconfirmed.

\section{Anaemia}

There remains considerable debate as to the desired haemoglobin level when considering whether a patient is suitable for weaning. Previous weaning guidelines referenced a haemoglobin target of $\geqslant 8-10 \mathrm{~g} \cdot \mathrm{dL}^{-1}$. In a large prospective randomised study, HEBERT et al. [99] have reported that a liberal red blood cell transfusion strategy maintaining haemoglobin concentration at $10-12 \mathrm{~g} \cdot \mathrm{dL}^{-1}$ does not decrease the duration of mechanical ventilation in critically ill patients. In a smaller group of COPD patients, transfusion led to a significant decrease of both the minute ventilation and the WOB [100]. Randomised controlled trials are needed to help define the appropriate target for different patient populations. The role of erythropoietin in selected patients needs further study.

\section{Recommendations}

Reversible pathology should be aggressively and repeatedly sought in all patients in groups 2 and 3. Ongoing surveillance for load, neuromuscular competence, metabolic, endocrine and nutrition issues is important. Emerging literature supports a search for CINMA and neuropsychological contributors to weaning failure.

\section{Further research}

Further research should include epidemiological evaluation of the pathophysiological contributors to weaning failure as the patient moves from acute critical illness with difficult weaning (group 2) to chronic critical illness with prolonged weaning (group 3).

\section{QUESTION 3: WHAT IS THE USUAL PROCESS OF INITIAL WEANING FROM THE VENTILATOR? \\ Assessing readiness to wean}

Prolonged mechanical ventilation is associated with significant morbidity and mortality. Therefore, weaning should be considered as early as possible in the course of mechanical ventilation. The process of initial weaning from the ventilator involves a two-step strategy. It begins with an assessment regarding readiness for weaning, which is then followed by SBT as a diagnostic test to determine the likelihood of successful extubation. In fact, for the majority of patients, the entire weaning process simply involves confirmation that the patient is ready for extubation. Patients who meet the criteria

\section{TABLE 5 Considerations for assessing readiness to wean}

Clinical assessment

Objective measurements

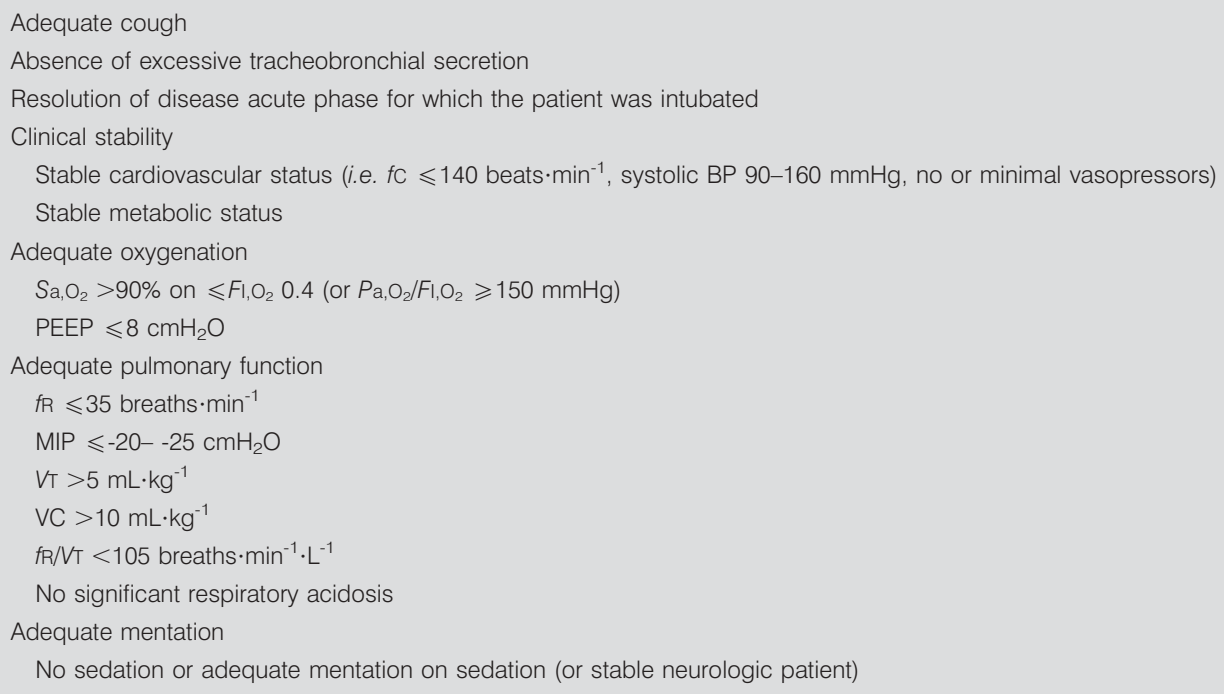

Data taken from $[5,6,13,16-18,22]$. $\mathrm{fC}$ : cardiac frequency; $\mathrm{BP}$ : blood pressure; $\mathrm{Sa}, \mathrm{O}_{2}$ : arterial oxygen saturation; $\mathrm{Fl}, \mathrm{O}_{2}$ : inspiratory oxygen fraction; $\mathrm{Pa}, \mathrm{O}_{2}$ : arterial oxygen tension; PEEP: positive end-expiratory pressure; fR: respiratory frequency; MIP: maximal inspiratory pressure; $V \mathrm{~T}$ : tidal volume; VC: vital capacity. $1 \mathrm{mmHg}=0.133 \mathrm{kPa}$. 


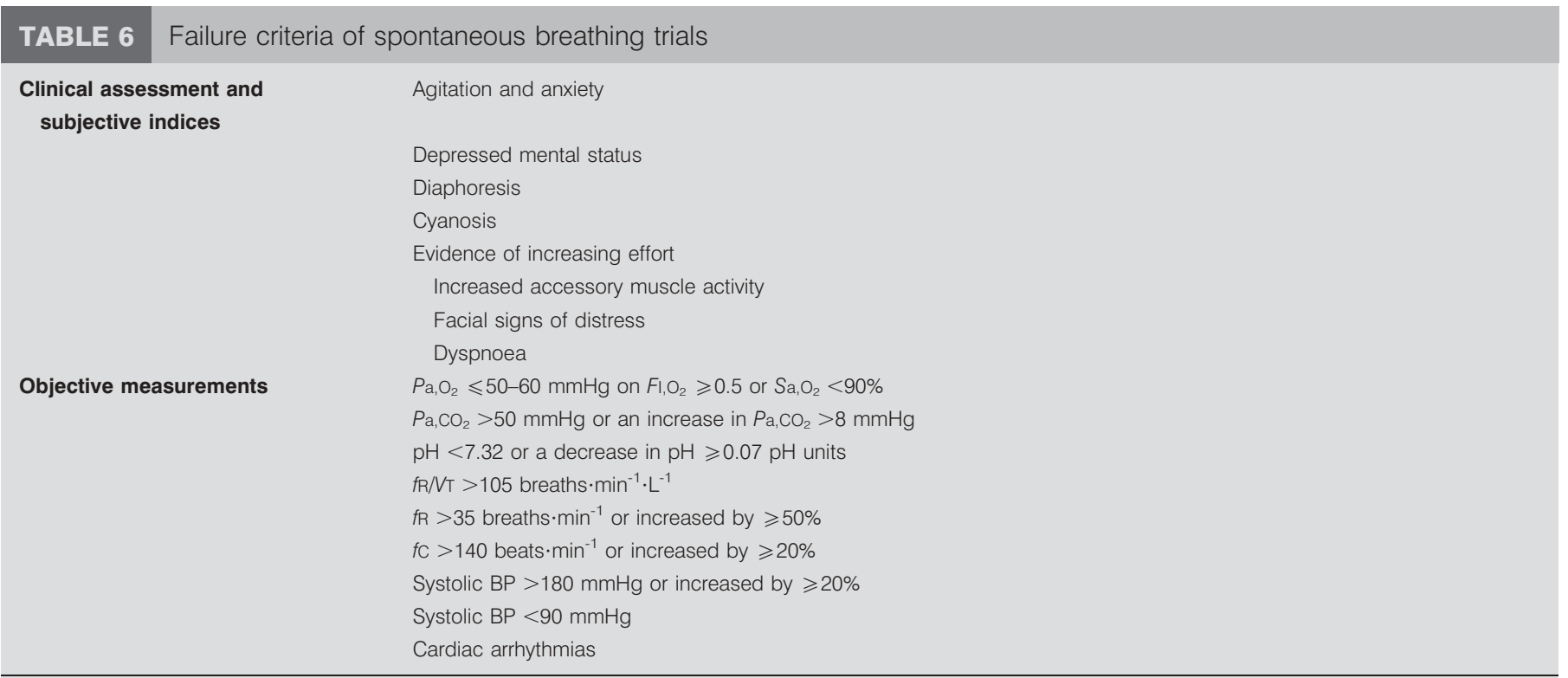

Data taken from $[16,18,19,62,116] . \mathrm{Pa}_{1} \mathrm{O}_{2}$ : arterial oxygen tension; $\mathrm{Fl}_{1} \mathrm{O}_{2}$ : inspiratory oxygen fraction; $\mathrm{Sa}, \mathrm{O}_{2}$ : arterial oxygen saturation; $\mathrm{Pa}$, $\mathrm{CO}_{2}$ : arterial carbon dioxide tension; fR: respiratory frequency; $V_{T}$ : tidal volume; fC: cardiac frequency; $\mathrm{BP}$ : blood pressure. $1 \mathrm{mmHg}=0.133 \mathrm{kPa}$.

reported in table 5 should be considered as being ready to wean from mechanical ventilation. Failing to extubate patients who can in fact be successfully weaned is more injurious than a failed SBT. Since many patients who do not meet all the criteria in table 5 are able to wean successfully from mechanical ventilation, these criteria should be viewed as considerations for probable weaning rather than as strict criteria that must all be met simultaneously.

The initial assessment of the readiness for discontinuation of mechanical ventilation support often involves calculation of the rapid shallow breathing index (RSBI). In general, patients should be considered for an RSBI calculation and subsequent SBT earlier rather than later, since physicians frequently underestimate the ability of patients to be successfully weaned. For many patients, discontinuation of sedation is a critical step that can be achieved by either daily interruption of sedation or continuous titration of sedation to a level that allows the patient to be adequately responsive [47]. An SBT should be considered as soon as possible once the patient meets the criteria in table 5; again, these criteria are to be taken as considerations rather than as rigid requirements. An initial assessment of the likelihood of a successful SBT is appropriate in order to avoid trials in patients with a high probability of failure. However, the predictive value of indices that attempt to predict successful SBT may be low in clinical practice. But it must be considered that pre-test probability of successful weaning, upon which predictive value of indices is based, may be very high because of the late measure of these indices in a majority of patients' course. The most commonly used test is calculation of the RSBI (respiratory frequency $(f \mathrm{R}) / V \mathrm{~T}$ ). A value $<100-105$ breaths $\cdot \mathrm{min}^{-1} \cdot \mathrm{L}^{-1}$ predicts a successful SBT with a reported sensitivity of 0.97 and specificity of 0.65 [62]. In patients in whom the clinical probability of successful weaning is high, the RSBI might be omitted.

\section{The spontaneous breathing trial}

Multiple studies have examined the methodology for performing an SBT. There appears to be no difference in either the percentage of patients who pass the SBT or the percentage of patients successfully extubated when a T-tube trial is compared with the use of low levels of pressure support (PS), such as $7 \mathrm{cmH}_{2} \mathrm{O}$ [6] or $8 \mathrm{cmH}_{2} \mathrm{O}$ [101] in adults or $10 \mathrm{cmH}_{2} \mathrm{O}$ [24] in paediatric patients, or the use of CPAP [102]. The use of automatic tube compensation (ATC), which adjusts for the assumed resistance of the endotracheal tube, is at least as successful as the use of simple T-tube or low-level PS [103]. PS has been used in previous studies with the purpose of overcoming the resistance of the endotracheal tube. These studies failed to account for the increased resistance of the inflamed natural upper airways following extubation, so that post-extubation WOB is best approximated without such compensation [38, 104]. Thus, it does not make sense to use PS for the purpose of overcoming the resistance of the endotracheal tube. The same line of reasoning applies to other modes of ventilation that have been proposed for this purpose, such as ATC. In the case of SBT failure because of a particularly narrow endotracheal tube, ATC may be beneficial. Studies demonstrate that patients who fail an SBT do so within the first $\sim 20 \mathrm{~min}[22,62]$, so the success rate for an initial SBT is similar for a 30-min compared with a 120-min trial [22, 105]. The need for a longer duration trial in patients who have previously failed weaning has not been adequately studied. The impact of low levels $\left(\leqslant 5 \mathrm{cmH}_{2} \mathrm{O}\right)$ of PEEP during an SBT has not been formally studied but is likely to be small. Due to dynamic hyperinflation, patients with COPD may have improved pulmonary function with CPAP. REISSMANN et al. [106] found that patients with COPD were more likely to pass a 30-min SBT when 5-7.5 $\mathrm{cmH}_{2} \mathrm{O}$ CPAP was supplied; however, the likelihood of successful extubation in patients who require CPAP during an SBT has not been studied. The increasing use of NIV 
(see Question 4) following extubation may make extubation more appropriate for such patients.

Criteria for passing SBT include respiratory pattern, adequate gas exchange, haemodynamic stability and subject comfort. Six large studies [16-18, 22, 24, 25] demonstrated that only $13 \%$ of patients who successfully passed the SBT and were extubated required reintubation (table 2). In patients who do not receive an SBT and are extubated, the failure rate is 40\% [107]. Patients who successfully pass the SBT should be extubated if neurological status, excessive secretions and airway obstruction are not issues. Although depressed mentation is frequently considered a contra-indication to extubation [108], Coplin et al. [13] demonstrated a low reintubation rate $(9 \%)$ in stable brain-injured patients with a Glasgow coma score $\leqslant 4$. $\mathrm{KOH}$ et al. [109] found that Glasgow coma score did not predict extubation failure. KHAMIEES et al. [110] demonstrated that poor cough strength and excessive endotracheal secretions were more common in patients who failed extubation following a successful SBT. In patients with neuromuscular ventilatory failure, a peak cough flow of $160 \mathrm{~L} \cdot \mathrm{min}^{-1}$ correlated with extubation success [111]. When upper airway obstruction due to oedema is a potential concern, a positive leak test (air leaks around the endotracheal tube after deflation of the cuff) is adequate before proceeding with extubation [112-115].

When patients fail an initial SBT, the criteria of which are reported in table 6, the clinician should review possible reversible aetiologies for failure (see Question 2; table 4). The SBT should be repeated frequently (daily) in order to determine the earliest time at which the patient can be successfully extubated. Although respiratory muscle fatigue has been considered to be a major reason for continuing failure to wean from mechanical ventilation, recent data demonstrate that weaning failure is not accompanied by low-frequency fatigue of the diaphragm [116].

Patients who fail the initial SBT should receive a nonfatiguing mode of mechanical ventilation (generally either assist-control or PSV). EsteBAN et al. [117] surveyed 412 ICUs in North America, South America, Spain and Portugal regarding ventilator modes and methods of weaning. The weaning method was PS in 36\%, synchronised intermittent mechanical ventilation (SIMV) in 5\%, SIMV and PS in $28 \%$, intermittent SBT in $17 \%$ and daily SBTs in $4 \%$. However, these data were obtained in 1996 and 1997, and subsequent trials demonstrating the inferiority of SIMV and the predictive value of daily SBT have changed these approaches. A subsequent study by ESTEBAN et al. [7] collected data from 361 ICUs in 20 countries during March 1998. EsTEBAN et al. [7] reported that weaning was performed with once-daily SBTs in $89 \%$, multiple weaning trials in $14 \%$, PS reduction in $21 \%$, SIMV in $8.5 \%$ and SIMV with PS in $22 \%$. The weaning trials were performed with T-tube in $52 \%$ of attempts, CPAP in $19 \%$, PS in $28 \%$ and flow in $1 \%$ [7]. The choice of mode of ventilation for patients who fail the initial SBT is discussed in Question 4.

\section{Weaning protocols}

Weaning protocols may be valuable in standardising the process of weaning. Physicians often fail to recognise patients who may already be ready for extubation. Studies among patients who are accidentally or self-extubated demonstrate that $23 \%$ of patients receiving full mechanical ventilation and $69 \%$ of patients who have begun weaning do not require reintubation [12, 118]. In fact, $35 \%$ of patients who were considered to be unweanable when referred from one facility to another could be extubated without any additional weaning attempts [26]. The percentage of patients who required weaning decreased from 80 to $10 \%$ when physician judgment was replaced by protocol management [119]. Protocol-directed daily screening of respiratory function and trials of SBT decrease the time required for extubation, the incidence of self-extubation, the incidence of tracheostomy and ICU costs, and results in no increase or even a decrease in the incidence of reintubation [6, 26, 120-126]. In trauma patients, DRIES et al. [127] reported a decreased incidence of ventilator-acquired pneumonia and death. Weaning protocols are less likely to be effective when the majority of patients are rapidly extubated [128], when physicians do not extubate patients following a successful SBT [108], or when the quality of critical care is already high [129]. Weaning protocols incorporating SBT may be particularly effective in helping physicians utilise the most effective techniques [5]. The use of ventilator bundles that ensure that all patients on mechanical ventilation receive standard therapies to prevent frequent complications, such as ventilator-acquired pneumonia and deep venous thrombosis, might be contemplated [130].

\section{Recommendations}

Weaning should be considered as early as possible in patients receiving mechanical ventilation; a majority of patients can be successfully weaned on the first attempt. SBT is the major diagnostic test to determine if patients can be successfully extubated. The initial SBT should last $30 \mathrm{~min}$ and consist of either T-tube breathing or low levels of PS $\left(5-8 \mathrm{~cm} \mathrm{H}_{2} \mathrm{O}\right.$ in adults; $\leqslant 10 \mathrm{cmH}_{2} \mathrm{O}$ in paediatric patients) with or without $5 \mathrm{cmH}_{2} \mathrm{O}$ PEEP. SIMV should be avoided as a weaning modality. Weaning protocols are most valuable in hospitals in which physicians otherwise do not adhere to standardised weaning guidelines.

\section{Further research}

Future studies should define the minimal criteria required for assessment of readiness for weaning (in order to allow earlier weaning), the need for a screening test such as the RSBI prior to the SBT, identification of patients who pass an SBT but fail extubation, the role of CPAP/PEEP in the COPD patient undergoing SBT, the required duration of the SBT in patients who fail the initial trial, and the specific aspects of weaning protocols which improve weaning outcome.

\section{QUESTION 4: IS THERE A ROLE FOR DIFFERENT VENTILATOR MODES IN MORE DIFFICULT WEANING?}

In patients requiring mechanical ventilation, weaning failure is relatively common, with an estimated prevalence of $31 \%$ and a range $26-42 \%[5,16,18,22]$. When initial attempts at spontaneous breathing fail to achieve the goal of liberation from mechanical ventilation, clinicians must choose appropriate mode(s) of ventilatory support which: 1) maintain a favourable balance between respiratory system capacity and load; 2) attempt to avoid diaphragm muscle atrophy; and 3) aid in the weaning process. 


\section{Pressure support ventilation}

PSV is commonly utilised and is the sole mode of mechanical ventilation used during the weaning process in $\sim 21 \%$ of patients [7]. PSV can be used during a SBT (not further discussed here) and as a weaning mode in both groups 2 and 3 (previously described). PSV used as the sole mode of mechanical ventilation during initial weaning attempts has been tested in two large randomised controlled trials. The study by BROCHARD et al. [18] involving 456 randomised patients determined that the use of PSV compared with SIMV and intermittent T-piece trials resulted in shorter duration of weaning ( $5.7 \pm 3.7$ days PSV versus $9.9 \pm 8.2$ days SIMV). During this protocol PSV was decreased from a mean of $19 \mathrm{cmH}_{2} \mathrm{O}$ by 2 or $4 \mathrm{cmH}_{2} \mathrm{O}$ per day. In 130 patients who had failed the initial SBT, ESTEBAN et al. [16] reported that either one daily trial or multiple daily trials of unassisted, spontaneous breathing (T-piece) more substantially reduced the duration of weaning than either SIMV or PSV, the median duration of weaning with each technique being $3,3,5$ and 4 days, respectively.

For those patients who have repeated difficulty tolerating weaning, i.e. group 3 as previously defined, PSV has also been observed to reduce the duration of mechanical ventilation (see Question 5) [26].

Lastly, it should be emphasised that in several trials (including those mentioned previously) intermittent use of spontaneous breathing via a T-tube was comparable to PSV as a weaning mode. Thus, after failed SBT, the use of progressively increased time on a T-piece is also an effective means of liberating patients from the ventilator.

Overall, there is consensus from the group and strong support from the literature for the use of PSV as a weaning mode after initial failed SBT (for group 2). The use of PSV may also be helpful in liberating patients from mechanical ventilation after several failed attempts at spontaneous breathing (group 3). The literature does not support the use of SIMV alone as a weaning mode and little data exist for the use of SIMV and PSV combined.

\section{Noninvasive ventilation}

In weaning, NIV has been studied for three different indications, which should be strictly separated. First, NIV has been used as an alternative weaning modality for patients who are intolerant of the initial weaning trial. Secondly, NIV has been used as a treatment option for patients who have been extubated but developed ARF within 48 h. Thirdly, NIV has been used as a prophylactic measure after extubation for patients who are at high risk for reintubation but who did not develop ARF.

\section{Alternative weaning technique for patients who failed} conventional weaning

Physiological studies suggest that similar levels of ventilatory support can be delivered by NIV compared to PSV in stable COPD patients who cannot tolerate spontaneous breathing. It has thus been hypothesised that in this select group of patients NIV: 1) might be useful as a bridge to total withdrawal of ventilatory support; and 2) would lower ICU morbidity. Four studies have been published in such a setting [27, 34, 131, 132].
In the majority of studied individuals, patients developed hypercapnia during initial attempts at weaning, and most patients had evidence of COPD. Despite failure of the SBTs, the intervention groups were extubated and placed on NIV via face mask with PSV set to a minimum inspiratory pressure of $15 \mathrm{cmH}_{2} \mathrm{O}$. The control groups were conventionally weaned with PSV (via standard mechanical ventilation) and extubated, but the details of this procedure are not specified in any of the four published papers. All trials were not blinded and the performing departments had expertise with NIV. Based on these trials the use of NIV for weaning shortened the total duration of invasive mechanical ventilation and ICU stay, and substantially reduced the rate of nosocomial infection. In two studies [27, 34], a significantly higher survival rate could also be found in the NIV group. However, two points need emphasis. First, although early extubation can avoid all of the complications of mechanical ventilation, the patients who fail SBTs may be sick with substantial comorbidities and at risk for extubation failure (discussed further later). Thus, although NIV is useful in very selected populations, its use cannot be recommended for all patients failing a SBT. Secondly, based on the definitions outlined in this statement, patients who are extubated to NIV should not be considered a weaning success until they are completely liberated from NIV as a form of therapy for ARF.

NIV as a prophylactic measure for patients with a high risk for reintubation

Prophylactic use of NIV has been studied in two populations of surgical patients. In two studies [133, 134] CPAP $\left(5-10 \mathrm{cmH}_{2} \mathrm{O}\right)$ was used to prevent reintubation in patients after major abdominal or vascular surgery. Compared with a control group (post-operative oxygen insufflation), CPAP (mean $7.5 \mathrm{cmH}_{2} \mathrm{O}$ ) improved oxygenation and reduced the rate of both reintubation and infection. In the study by BOHNER et al. [133] reintubation rate was not significantly reduced with CPAP. In both studies there was a trend towards a shorter stay in the hospital and a better survival. Lastly, studies are underway for patients from groups 2 and 3 who are at high risk for extubation failure. However, no firm recommendations can be made for this select group of patients.

NIV for the treatment of respiratory insufficiency after extubation (post-extubation failure)

Post-extubation failure is defined mainly by clinical criteria (table 7). It has a mean prevalence of $6.3-17.7 \%$ and is associated with increased ICU mortality. Two small singlecentre trials $[135,136]$ studied organ transplant patients who

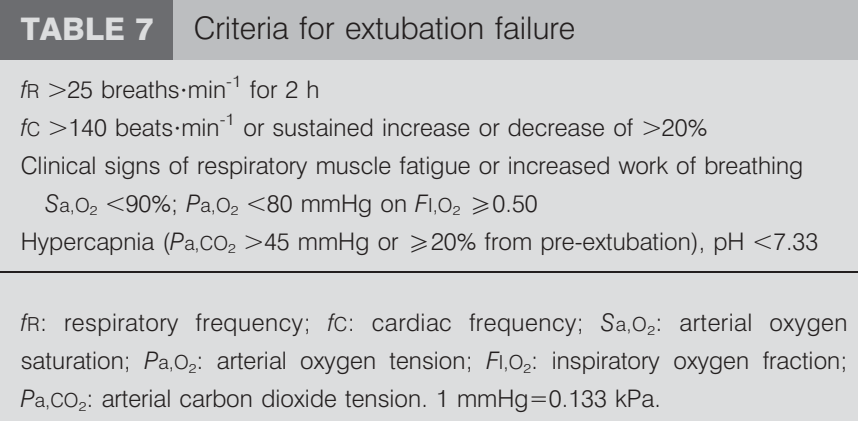


developed respiratory insufficiency after extubation. NIV improved oxygenation and reduced the $f R$ significantly, compared with oxygen insufflation alone. PSV was also superior to PEEP [135]. In the study by ANTONELLI et al. [136], the reintubation rate and the duration of ICU stay were lower in the control group, but neither study revealed an advantage in terms of mortality.

In two large randomised, multicentre studies [137, 138], NIV was evaluated for treatment of acute respiratory insufficiency occurring in the first $48 \mathrm{~h}$ after extubation and was compared with standard oxygen therapy. Neither study showed advantages for the use of NIV. In the study by ESTEBAN et al. [138], the NIV group had worse survival compared with the oxygen group. The authors hypothesised that a 10-h delay in reintubation was the cause of the increased mortality in the NIV group [138]. However, both studies have important limitations: in the study by KEENAN et al. [137], it is probable that both the inspiratory and expiratory pressures set on the ventilator (10 and $5 \mathrm{cmH}_{2} \mathrm{O}$, respectively) were too low, and, as the authors point out, the experience of the ICU staff with NIV was limited. The trial conducted by EsTEBAN et al. [138] focused mostly on patients with mild respiratory failure (mean $f \mathrm{R}$ 29 breaths $\cdot \mathrm{min}^{-1}$, $\mathrm{pH} 7.39, \mathrm{~Pa}_{1} \mathrm{CO}_{2} 46 \mathrm{mmHg}, \mathrm{Pa}_{1} \mathrm{O}_{2} 79 \mathrm{mmHg}$, at the time of randomisation) and the different modes, ventilator type or settings for mechanical ventilation were not clear. In addition, the criteria for the discontinuation of NIV and the crossover of control patients to NIV were unclear. Lastly, a post hoc analysis of this data revealed a lower reintubation rate for the small number $(10 \%)$ of patients with COPD included in the trial [138]. Overall, the literature does not support the use of NIV as a treatment for extubation failure.

One important issue to emphasise in all of the NIV trials is patient mix and aetiology of the respiratory failure being treated. The evidence for use of NIV in COPD patients and those with hypoxic respiratory failure with concomitant hypercapnic respiratory failure is substantially stronger than in other groups. Careful patient selection is imperative for the use of NIV and for future study design.

In conclusion, NIV cannot generally be recommended for any of the specific topics mentioned previously. However, there is promise that for some subgroups (hypercapnic respiratory insufficiency, especially in COPD patients) NIV may be helpful in expediting the weaning process. Clear criteria for discontinuation of NIV must be defined. Positive effects of a prophylactic CPAP or NIV treatment in patients at risk for reintubation seem likely, but larger studies have yet to confirm this observation.

\section{Continuous positive airway pressure}

$\mathrm{CPAP}$ applied during spontaneous breathing in patients with acute respiratory insufficiency reduces mean intrathoracic pressure, has beneficial effects on right and left ventricular performance [40, 139], improves oxygenation [134] and reduces the WOB [140]. From a physiological point of view, additional application of PEEP either alone or with PSV seems logical for weaning. However, few prospective studies are available. FEELEY et al. [141], in a randomised controlled trial, concluded that PEEP in spontaneously breathing patients may be helpful during weaning of patients with primarily hypoxic respiratory failure. In cardiac surgical patients, typically included in the previously discussed weaning group 1, BAILEY et al. [142] randomised patients to receive CPAP or T-piece trials prior to extubation and observed no significant difference in oxygenation or time spent on mechanical ventilation. Others have hypothesised that the use of CPAP during weaning may be helpful to prevent immediate postextubation hypoxaemia; however, compared to T-piece trials no clear improvement in outcomes has been observed. Lastly, CPAP has been used for prophylaxis against post-operative extubation failure. SQUADRONE et al. [134] observed, in a multicentre randomised controlled trial, that CPAP compared to oxygen supplementation substantially reduced the reintubation rate.

In summary, for group 1 patients, CPAP may be an alternative to standard weaning modes, although its application in group 2 and 3 patients has not been clearly evaluated. In addition, although combinations of CPAP and PSV are commonly applied during the weaning period, there is also a lack of prospective randomised controlled trials to suggest that CPAP is superior to other techniques such as PSV alone or T-tube in the process of weaning from invasive mechanical ventilation.

\section{Automatic tube compensation}

The use of ATC, a ventilatory method aimed at compensating for the nonlinear pressure drop across the endotracheal tube during spontaneous breathing, is at least as successful as the use of simple T-tube or low-level PS for weaning from mechanical ventilation [103]. If an SBT fails because of a particularly narrow endotracheal tube, ATC may be beneficial. For more difficult weaning patients (groups 2 and 3 ) there is a lack of controlled trials to make any meaningful recommendations about the use of ATC.

\section{Proportional assist ventilation}

The physiological response to proportional assist ventilation (PAV) has been studied in ventilator-dependent patients with COPD. In comparison to PSV and CPAP, there was no substantial difference in oxygenation, pressure time product and other physiological variables. Only when CPAP was combined with PAV was a more substantial change in these parameters notable [143-145]. PAV is available with some respirators but its application is sometimes regarded as difficult and has not been investigated thoroughly in weaning trials.

\section{Servo-controlled ventilation}

Rapid adaptation of the ventilatory support to the changing situations of a patient is one of the major factors determining the length of the weaning process. However, ICU staff resources are often too limited to allow immediate response. Automatic ventilatory modes provide a tool to achieve optimal ventilatory support and an individual level of PS with the aim of rapid extubation. Two such modes, adaptive support ventilation (ASV) and a knowledge-based expert system (Smartcare $\left.{ }_{\mathbb{R}}\right)$, have been integrated into conventional intensive care ventilators and are available on the market.

\section{Adaptive support ventilation}

ASV is based on a computer-driven closed-loop regulation system of the ventilator settings which is responsive to changes 
in both respiratory system mechanics and spontaneous breathing efforts [146]. At the beginning of mechanical ventilation, the clinician enters the patient's body weight and sets the desired percentage of minute ventilation (100\% being equal to $100 \mathrm{~mL} \cdot \mathrm{kg}^{-1}$ body weight $\cdot \mathrm{min}^{-1}$ in adult patients), as well as the $\mathrm{FI}, \mathrm{O}_{2}$, level of PEEP and maximal inspiratory pressure. Thereafter, mechanical ventilation starts with closed-loop regulation algorithms based on real-time determination of the expiratory time constant [147]. Adjustment of inspiratory pressure, duty cycle and $f R$ (to ensure an $f R$ and minute ventilation within defined limits) may improve patient-ventilator interactions. Any spontaneous breathing efforts trigger either a pressure-controlled breath or a spontaneous breath with inspiratory PS, the level of which is adjusted to meet the target $f \mathrm{R} / V \mathrm{~T}$ combination. ASV can thus manage the spectrum of ventilatory support ranging from controlled mechanical ventilation to PS, up to the pre-extubation weaning trial.

Two nonrandomised trials $[148,149]$ and one randomised trial [150] evaluating ASV during weaning have been published, all focused on post-cardiac surgery patients. Earlier extubation and fewer ventilator adjustments, as well as a reduced need for arterial blood gas measurements and high-pressure alarms have been documented [150]. However, these results should be interpreted with caution, as ASV was compared with SIMV, which has been shown to be the worst weaning mode [16] Therefore, further studies comparing ASV with other weaning techniques are necessary to gain insights of the utility of this mode.

\section{Knowledge-based expert system}

This system, which is presently integrated in a standard ICU ventilator (Evita XL; Dräger, Lübeck, Germany) under the brand name Smartcare ${ }^{\circledR}$, has been developed over several years and is based on fuzzy logic algorithms [151, 152]. The system follows two main goals. The first is a real-time adaptation of the level of pressure support to maintain the patient within a "comfort" zone. This is defined as a fR of 1530 breaths $\cdot \mathrm{min}^{-1}$ (ranging up to 34 breaths $\cdot \mathrm{min}^{-1}$ in patients with neurological disease), a $V \mathrm{~T}$ above minimum threshold ( $250 \mathrm{~mL}$ if body weight is $<55 \mathrm{~kg}$ and $300 \mathrm{~mL}$ otherwise) and an end-tidal expiratory carbon dioxide below maximum threshold $(7.3 \mathrm{kPa}(55 \mathrm{mmHg})$ or $8.6 \mathrm{kPa}(65 \mathrm{mmHg})$ in patients with COPD). To reach these targets, the level of PS is periodically adapted by the system in steps of $2-4 \mathrm{cmH}_{2} \mathrm{O}$. Secondly, the device also includes an algorithm of a stepwise decrease of PS with the aim of automatically performing an SBT. The system has been shown to maintain a patient in the comfort zone more successfully than clinician-directed adjustments [153]. Additional studies are needed to evaluate its efficacy in difficult weaning.

\section{Controlled mechanical ventilation}

Older studies have suggested that in patients weaning from mechanical ventilation there is evidence of diaphragm fatigue and possibly injury. This may occur because the load on the respiratory muscles of patients who fail to wean is increased to levels that would predictably produce fatigue in the respiratory muscles if patients were allowed to continue spontaneous breathing without ventilator assistance (i.e. the tension-time index is substantially increased). Thus, by this logic, the use of controlled mechanical ventilation (CMV) to rest the fatiguing diaphragm seems reasonable. However, LAGHI et al. [116] demonstrated that, despite greater load and diaphragmatic effort, weaning failure patients do not develop low-frequency muscle fatigue, although these patients displayed diaphragmatic weakness. Furthermore, a number of animal studies have demonstrated that CMV induces diaphragm muscle injury (ventilator-induced diaphragm dysfunction) [94]. This phenomenon occurs in animals and is evident after short-term application of CMV. The aetiology is unknown but the observed decrease in diaphragm compound action muscle potentials has been attributed to oxidative stress within the muscle and muscle atrophy. Whether the diaphragm damage attributed to controlled ventilation is indeed larger than during assist-control or PSV remains unclear. Therefore, there is no clear advantage of CMV compared with other ventilatory modes in patients with difficult weaning (group 2).

\section{Recommendations}

In group 2 and 3 patients (patients failing prior attempts at SBT), PSV or assist-control ventilation should be favoured. NIV techniques to shorten the duration of intubation should be considered in selected patients, especially those with hypercapnic respiratory failure. NIV should not be routinely used as in the event of extubation failure and should be used with caution in those patients with hypoxic respiratory failure. CPAP may be effective in preventing hypoxic respiratory failure in patients after major surgery; otherwise there is no clear advantage over other modes of mechanical ventilation used during weaning. Servo-controlled ventilation may be an additional tool for reducing time on mechanical ventilation; however, the numbers of studies are too limited to make firm recommendations.

\section{Further research}

In group 2 and 3 patients, well-designed randomised controlled trials comparing different modes of mechanical ventilation and the physiological impact on weaning are needed. Investigating the impact of ventilator-induced muscle injury and fatigue in humans is necessary.

\section{QUESTION 5: HOW SHOULD PATIENTS WITH PROLONGED WEANING FAILURE BE MANAGED?}

A significant number of patients will experience prolonged weaning failure despite multiple weaning attempts following SBTs. Although specific epidemiological data do not exist, one study showed that this population represents $\sim 10 \%$ of ICU admissions and consumes a significant amount of the overall ICU patient-days and $\sim 50 \%$ of financial resources [154]. Two other studies demonstrated that up to $20 \%$ of medical ICU patients remained dependent on ventilatory support after 21 days $[155,156]$.

Assuming that reversible factors have been optimised (e.g. cardiac, metabolic, etc.), the eventual clinical outcome of patients with prolonged weaning failure will depend on the long-term trajectory of the underlying disease. Studies have shown that patients with neuromuscular and chest wall disorders are less likely to be weaned completely compared with patients with COPD. However, the former patients have decreased mortality compared with patients with COPD, who have the highest mortality [157]. 


\section{The role of tracheostomy}

Tracheostomy has become an increasingly common intervention in ICUs [158] with the introduction of percutaneous techniques performed by the intensivist at the bedside [159]. It would now be unusual for clinicians to persist with orotracheal intubation in patients perceived as being difficult to wean, in the absence of contra-indications to tracheostomy.

Proposed advantages for tracheostomy include easier airway management, improved patient comfort and communication, reduction in sedative use, earlier weaning from respiratory support, improved respiratory mechanics, earlier transition to oral feeding, reduced oropharyngeal trauma and prevention of ventilator-acquired pneumonia [156, 160]. Adverse effects include misplacement, haemorrhage, obstruction, displacement, impairment of swallowing reflexes and late tracheal stenosis. Conversely, clinicians should also consider the possibility that tracheostomy promotes only short-term survival and increases the proportion of dependent survivors suffering a heavy burden of chronic disease [158].

\section{Patient comfort and sedation}

The benefits of minimising sedation $[47,161]$ might be easier to achieve with a tracheostomy rather than an orotracheal tube. Also, nurses consider that tracheostomy is more comfortable for patients undergoing prolonged weaning [162]. A small prospective survey found that only four out of 20 patients shared this view [163]. Such research is complicated by problems with patient recall and communication.

Technical, mechanical and safety aspects

Tracheostomy may offer a more secure airway than a translaryngeal tube [160] with fewer accidental extubations, though this will also reflect issues of staffing and expertise. Tracheostomy may reduce WOB by improving some aspects of pulmonary mechanics [164, 165], but there is no evidence that this is linked to reductions in weaning time or length of stay. Although several studies report reduced ventilator-acquired pneumonia rates in patients with a tracheostomy compared with orotracheal tubes [166-169], this effect is inconsistent [170, 171] and most studies are methodologically weak. The issue requires further examination linked to studies examining timing of tracheostomy.

\section{Timing of tracheostomy}

Although prolonged translaryngeal intubation causes tissue trauma, promotes bacterial translocation and infection, and usually requires sedation to reduce patient discomfort, there is little evidence to guide optimal timing for a tracheostomy, in part because of the methodological diversity in the 15 studies and one systematic review which have been conducted in this area (table 8) [109, 160, 166-169, 172-181]. Only eight of these studies are randomised controlled trials, four of which have been published since 1997 [168, 169, 172, 173]. RUMBAK et al. [169] screened 135 medical ICU patients to perform a prospective randomised study of 120 patients, with weaning and sedation protocols used to standardise care between groups. Early tracheostomy (within 2 days of admission) halved 30-day mortality rate and reduced pneumonia, accidental extubation and ICU length of stay. However, 10 out of 60 patients randomised to deferred tracheostomy weaned from ventilation without requiring this intervention, emphasising the need for better predictors of ventilator dependence [182184]. Such predictors will need to take into account variable weaning techniques and their generalisability will be affected by case-mix variation and prior probabilities of weaning in different populations. A smaller randomised study in 44 patients with burns showed no advantage to tracheostomy performed on average at day 4 post-burn [173].

Prospective randomised trials to determine the most appropriate timing for tracheostomy will need to: ensure equipoise between participating centres; define "early"; and consider the impact of case-mix variation. Evaluation should include patient-centred outcomes.

\section{Outcome}

Cohort studies report longer duration of mechanical ventilation and ICU and hospital stay in tracheostomised patients [156, 185187]. Effects on mortality are inconsistent $[185,188]$. A retrospective 3-yr review of 549 patients with tracheostomy reported poor survival and functional outcomes [186]. The rate of tracheostomy in the North Carolina Medicare database [158] has increased over a $10-y r$ period from 8.3 to 24.2 cases per 100,$000 ; 25 \%$ of patients died in hospital, $23 \%$ were discharged to a skilled-nursing facility, $35 \%$ were discharged to rehabilitation or long-term care units, and only $8 \%$ were discharged home. There are few prospective randomised controlled studies that have evaluated these factors objectively from the patients' perspective and in terms of longer-term outcomes. The absence of such studies may reflect lack of equipoise amongst clinicians or a feeling that tracheostomy is a pragmatic approach to patient care which does not require evaluation. Research methodologies will need to adjust for local circumstances such as existence of long-term weaning facilities.

\section{Percutaneous tracheostomy}

Percutaneous dilational tracheostomy is increasingly utilised as an alternative to conventional surgical tracheostomy. A recent meta-analysis demonstrated this technique to be associated with fewer complications compared with surgical tracheostomy [189]. No difference was observed between the two techniques regarding overall procedure-related complications or death. A recent prospective, randomised study comparing percutaneous dilational tracheostomy with surgical tracheostomy in critically ill patients demonstrated the former to be a cost-effective alternative to surgical tracheostomy with no difference in ICU or hospital length of stay. The reduction of costs resulted from the procedure being performed in the ICU rather than consuming operating room facilities and personnel [190].

\section{Rehabilitation}

Rehabilitation is the process of restoring health or normal life by training and therapy after illness, but it would seem preferable to do this proactively by optimising and preserving physiological reserve at the earliest possible stage in acute disease, as well as trying to restore it during the later phases of chronic critical illness.

Patients who survive the acute phase of critical illness experience a wide range of physical disabilities [74], including: neuromyopathies; muscle wasting, weakness and fatigability; 


\begin{tabular}{|c|c|c|c|c|c|c|}
\hline First author [Ref.] & Yr & $\begin{array}{l}\text { Study } \\
\text { topic }\end{array}$ & Design & $\begin{array}{c}\text { Subjects } \\
\mathrm{n}\end{array}$ & $\begin{array}{c}\text { Patient } \\
\text { characteristics }\end{array}$ & $\begin{array}{c}\text { Comparator in prospective } \\
\text { studies }\end{array}$ \\
\hline RUMBAK [169] & 2004 & Early versus late & RCT & 120 & Medical ICU & $<2$ days versus $12-14$ days \\
\hline BOUDERKA [172] & 2004 & Early versus late & $\mathrm{RCT}$ & 62 & Head injury & $\begin{array}{c}\text { Tracheostomy day } 5 \text { versus } \\
\text { orotracheal tube }\end{array}$ \\
\hline SAFFLE $[173]$ & 2002 & Early versus late & $\mathrm{RCT}$ & 44 & Burns & $\begin{array}{c}\text { Mean } 4 \text { days versus } 14.8 \text { days } \\
\text { post-burn }\end{array}$ \\
\hline TEOH [174] & 2001 & Early versus late & Retrospective & 30 & Neurological ICU & \\
\hline BROOK [175] & 2000 & Early versus late & $\begin{array}{l}\text { Prospective } \\
\text { observational }\end{array}$ & 90 & Medical ICU & $<$ Day 11 \\
\hline MAZIAK [176] & 1998 & Timing & Systematic review & & & \\
\hline ARMStRong [177] & 1998 & Early versus late & Retrospective & 157 & Blunt trauma & \\
\hline Sugerman [168] & 1997 & Early versus late & $\mathrm{RCT}$ & 155 & Trauma & $3-5$ days versus $10-14$ days \\
\hline ВLOT [178] & 1995 & Early versus late & Retrospective & 53 & Neutropaenia & \\
\hline D’AmeLıo [179] & 1994 & $\begin{array}{l}\text { Early plus PEG } \\
\text { versus late }\end{array}$ & $\begin{array}{l}\text { Prospective } \\
\text { case series }\end{array}$ & 31 & Head injury & $\leqslant 7$ days versus $>7$ days \\
\hline LESNIK $[\mathbf{1 8 0}]$ & 1992 & Early versus late & Retrospective & 101 & Blunt trauma & \\
\hline RODRIGUEZ [167] & 1990 & Early versus late & $\mathrm{RCT}$ & 106 & Blunt trauma & $1-7$ days versus $>7$ days \\
\hline DUNHAM [166] & 1984 & Early versus late & $\mathrm{RCT}$ & 74 & Blunt trauma & \\
\hline StAufFer [160] & 1981 & $\begin{array}{c}\text { Early tracheostomy } \\
\text { versus orotracheal } \\
\text { tube }\end{array}$ & $\mathrm{RCT}$ & 150 & Mixed medical/surgical & $\begin{array}{c}\text { Tracheostomy day } 5 \text { versus } \\
\text { orotracheal tube }\end{array}$ \\
\hline EL-NAGGER [181] & 1976 & $\begin{array}{c}\text { Early tracheostomy } \\
\text { versus orotracheal } \\
\text { tube }\end{array}$ & $\mathrm{RCT}$ & 52 & Acute respiratory failure & $\begin{array}{c}\text { Tracheostomy day } 3 \text { versus } \\
\text { orotracheal tube }\end{array}$ \\
\hline
\end{tabular}

RCT: randomised controlled trial; ICU: intensive care unit; PEG: percutaneous endoscopic gastrostomy

joint deformities and contractures; and the additional residual disease-related damage to specific organ systems. Patients who remain ventilator-dependent in the ICU may suffer the additional burden of continued systemic inflammation and catabolism combined with limited mobility and suboptimal nutrition, and this particularly affects the neuromuscular system. One study showed that $62 \%$ of difficult-to-wean patients had neuromuscular disease sufficiently severe enough to account for ventilator dependency [48]. These observations suggest that efforts to prevent or treat respiratory muscle weakness might have a role in reducing weaning failure.

Rehabilitation efforts have focused on improving muscle power and endurance through passive and active movements, posture and different forms of exercise. Many studies show effects of modest magnitude on various surrogate measures, such as respiratory physiology, oxygen consumption, muscle fibre atrophy and protein loss. There is, however, a lack of studies demonstrating an impact of rehabilitation on the prevention or reversal of weaning failure or other clinically important outcomes.

In addition to neuromuscular disorders, patients experience other physical and psychosocial effects, such as: changes to skin and hair; endocrine impairment; disorders of sleep, mood and libido; and pain. The high symptom burden of survivors of chronic critical illness is accompanied by mortality rates of $\sim 50 \%$ at 3 months [191]. Close family members are also affected by what is in effect a form of post-traumatic stress syndrome [192]. Since multifaceted interventions such as self-help rehabilitation programmes can improve physical function after critical illness [193], it is possible that improvements in clinical outcomes for difficult-to-wean patients might be achieved using a methodology similar to that of ventilator bundles.

\section{Specialised weaning units}

Acute care units probably lack the necessary focus, personnel and organisational structure to care for patients with prolonged weaning failure. In contrast, specialised weaning units (SWUs) offer specialised teams (e.g. nurses, physiologists, respiratory therapists, nutritionists, etc.) and an appropriate "bridge to home" environment for such patients and their families (e.g. privacy, daytime activity, longer visiting hours and undisturbed sleep). They also relieve pressure on scarce ICU beds.

These units can be of two types: 1) step-down units or noninvasive respiratory care units within acute care hospitals; and 2) regional weaning centres that serve several acute care hospitals within the region. The type of unit preferable will depend on the healthcare structure and financing system of each individual region or country.

Observational studies indicate that $34-60 \%$ of patients in SWUs can be weaned successfully from ventilatory support. These 
studies also suggest that successful weaning can occur up to 3 months after admission to these units. More importantly, the long-term mortality rate is not adversely affected by the transfer to an SWU [194, 195]

Of the successfully weaned patients, $\sim 70 \%$ (range $50-94 \%$ ) are discharged home alive; however, the 1-yr survival rate for these patients ranged $38-53 \%$. Hence, only $5-25 \%$ of patients admitted to a specialised weaning facility can be expected to be ventilator independent and alive at home $1 \mathrm{yr}$ after their initial respiratory failure (fig. 2) [196-201].

The clinical outcome of patients requiring prolonged mechanical ventilation is largely driven by the underlying disease. For example, one study showed that weaning success was highest in post-operative patients $(58 \%)$ and those with acute lung injury $(57 \%)$, and lowest in patients with COPD or neuromuscular disease (22\%) [202]. The long-term survival rate after successful weaning is worse in patients with severe COPD compared with non-COPD patients [201].

Few studies have compared outcomes of care between SWUs and ICUs. A controlled historical study by GRACEY et al. [198] showed that the mortality rate decreased significantly after a dedicated ventilator unit had been opened inside an acute care hospital. However, given service pressures and financial constraints, it is unlikely that randomised controlled comparisons will be performed.

SWUs may be cost-effective alternatives to acute ICUs. Several observational studies estimate lower daily costs of care for ventilator-dependent patients in SWUs [157, 203-205], primarily through lower salaries, and reduced building charges, monitoring (e.g. noninvasive), technical equipment (e.g. portable ventilators), cost of diagnostics and therapeutics.

Weaning strategies used in SWUs have included intermittent mandatory ventilation/PS, PSV, and T-tube trials [26, 202, 203, 206, 207]. VITACCA et al. [26] studied 75 COPD patients

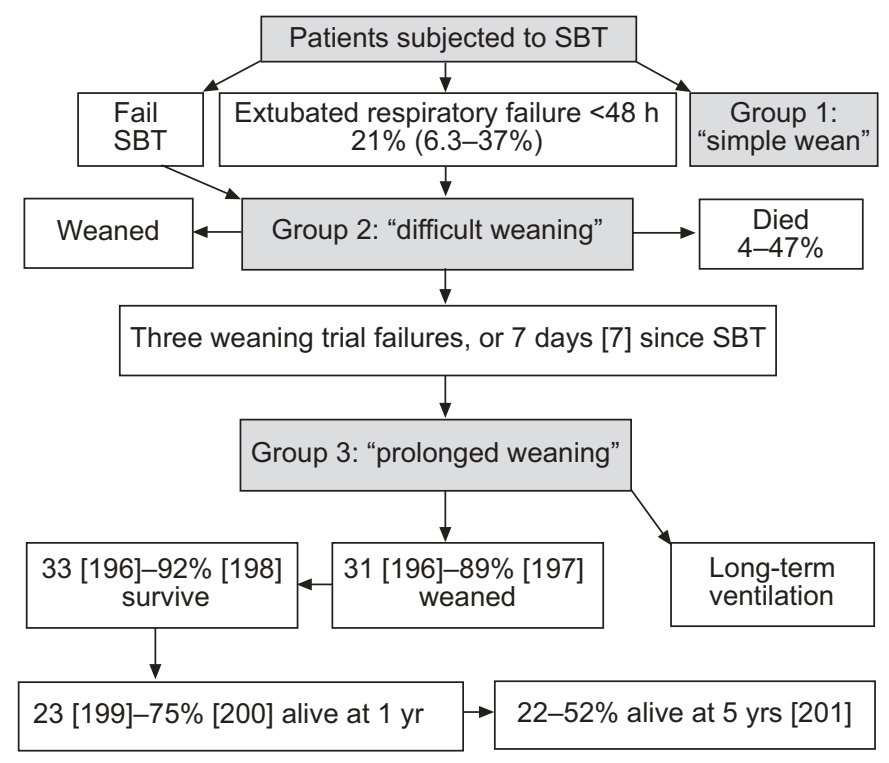

FIGURE 2. Mortality and weaning process in patients with prolonged weaning failure. SBT: spontaneous breathing trial. randomised to PSV or T-tube SBT, both of which were delivered via the use of protocols. No significant difference was found in weaning success rate $(73$ versus $77 \%$ in the PSV and SBT group, respectively) and mortality rate (11.5 versus $7.6 \%$ ). However, when the outcomes of applying these defined protocols were retrospectively compared with prior uncontrolled clinical practice, the 30-day weaning success rate was significantly greater (87 versus $70 \%$ ). Thus, in difficult-to-wean patients, the use of clearly defined protocols, independent of the mode used, may result in better outcomes than uncontrolled clinical practice.

Many issues remain unresolved for SWUs. These include admission criteria, minimum operating standards and staff qualifications. Although some SWUs accept every ventilatordependent patient, most apply admission criteria, such as two documented failed weaning trials [198], the presence of a tracheostomy tube, clinical stability and the potential to benefit from rehabilitation [208, 209]. These criteria may (appropriately) select patients who are more likely to benefit but may also favourably influence the outcome data of individual SWUs. Standards for the establishment of SWUs might include acceptable nurse/patient ratios, the requirement for a supervising pulmonary physician, qualifications of respiratory therapists and the presence of certain specialised staff members (e.g. nutritionists, psychologists, etc.). Without such benchmarking, the possibility exists of transferring patients from a well-functioning ICU to a less-than-optimal SWU.

\section{Home ventilation}

As previously noticed, a significant number of patients with prolonged weaning failure remain ventilator dependent, requiring long-term ventilatory support, which may now be provided as NIV in the home setting. A study from Cleveland (OH, USA) [208] in patients following ARDS, cardiothoracic surgery or with COPD showed that $9 \%$ of patients were discharged home with partial ventilatory support, with $1 \%$ using NIV and $8 \%$ requiring partial mechanical ventilation via the tracheostomy. SCHÖNHOFER et al. [201] showed that in a predominantly COPD population, $75 \%$ were discharged home from an SWU, of whom 31.5\% required home NIV. A UK study [157] reported that of surviving patients, $38 \%$ were fully weaned and $35 \%$ required further home ventilation, with the majority using NIV.

\section{Terminal care for the ventilator-dependent patient}

Studies have measured the quality of life of patients after prolonged mechanical support [210-212] and of those patients receiving home mechanical ventilation [213-217]. While these studies report varying results, there are a significant number of patients who rate their quality of life as being low. Patients with COPD rate their quality of life lower than those patients with neuromuscular disorders [216]. The existence of a poor quality of life coupled with the prospect of low survival rates might prompt autonomous patients who are ventilator dependent to consider withdrawal of mechanical ventilation or those who are not ventilator dependent may decide to forgo future ventilatory attempts. Shared decision making is the most appropriate model for forgoing life-sustaining support, and clinicians will need to provide accurate prognostic 
information because such information has been shown to influence patients' preferences regarding resuscitation [218].

When patients lack decision-making capacity, the laws of individual regions and countries will determine the legal permissibility of surrogates' (medical or nonmedical) decisions to forgo life-sustaining support. These laws, and the circumstances in which they may be applied, vary widely, and in some European countries are currently under review. There are also substantial personal, religious and cultural biases which affect the behaviour of care givers [219, 220]. Of concern are studies demonstrating poor communication between the physicians of critically ill patients and their families [221] or termination of support without family input [222]. SWUs should ensure that these issues are openly discussed and incorporated in management policies.

Several recent studies suggest that routine palliative care or ethics consultation can improve the quality of decision making regarding withdrawing mechanical ventilation in the acute ICU setting [223-225]. Input from palliative care specialists and ethicists in the chronic setting would seem appropriate as well. Several commentators offer guidance for clinicians in the practical aspects of withdrawing mechanical ventilation, including the development of a standardised order form for the withdrawal of life support in the ICU [226, 227].

\section{Recommendations}

Studies of rehabilitation should examine multifaceted interventions focused on improving patient-centred outcomes. Care bundles might be a relevant research methodology for this purpose. SWUs may be cost-effective for certain groups of patients with prolonged weaning failure but guidelines are needed for admission criteria, minimum structural and operating standards, and risk-adjusted benchmarks that permit assessment of efficacy and safety. NIV in the home setting might be considered an option for patients with prolonged weaning failure after careful attention to home discharge planning. Decisions to withhold or withdraw mechanical ventilatory support should reflect a shared decision-making model that is informed by a full disclosure of prognostic data and should be based on patient-centred interests and values.

\section{Further research}

Adequately powered clinical studies of tracheostomy should evaluate optimal timing and longer-term patient-centred outcomes. Controlled studies are needed to assess the impact of mechanical ventilatory support after hospitalisation, especially in chronic obstructive pulmonary disease patients, addressing outcomes such as exacerbation frequency, health status and costs. Further studies are required to delineate the process of terminal discontinuation of ventilatory support in specialised weaning units.

\section{ACKNOWLEDGEMENTS}

International Consensus Committee members: M. Levy (Boston, MA, USA) and M. Zelter (Paris, France). Scientific advisors: M. Elliott (Leeds, UK) and M. Tobin (Hines, IL, USA). Experts who wrote reports and delivered presentations: J. Mancebo (Barcelona, Spain), P. Navalesi (Pavia, Italy), S. Epstein (Boston), S. Carson (Chapel Hill, NC, USA), M.
Polkey (London, UK), T. Similowski (Paris), M.R. Pinsky (Pittsburgh, PA, USA), M.W. Elliott (Leeds), F. Laghi (Hines), A. Torres (Barcelona), B. de Jonghe (Poissy, France), A. Jubran (Hines), M. Tobin (Hines), L. Brochard (Créteil, France), C. Sassoon (Long Beach, CA, USA), M. Vitacca (Gussago, Italy), T. Vassilakopoulos (Athens, Greece), A. Rossi (Bergamo, Italy), S. Nava (Pavia, Italy), N. Hill (Boston), P. Jolliett (Geneva, Switzerland), B. Schönhofer (Hannover, Germany), E. L'Her (Brest, France), R. Gosselink (Leuven, Belgium), J.R. Curtis (Seattle, WA, USA). Jury: J-M. Boles (chairman; Brest), J. Bion (Birmingham, UK), A. Connors (Cleveland, OH, USA), M. Herridge (Toronto, Canada), Brian Marsh (Dublin, Ireland), Christian Melot (Brussels, Belgium), Ronald Pearl (Stanford, CA, USA), Henry Silverman (Baltimore, MD, USA), Michael Stanchina (Providence, RI, USA), Antoine Vieillard-Baron (Boulogne, France), Tobias Welte (Hannover, Germany).

\section{REFERENCES}

1 Carlet J, Artigas A, Bihari D, et al. The first European Consensus Conference in Intensive Care Medicine: introductory remarks. Intensive Care Med 1992; 18: 180-181.

2 National Institutes of Health, Office of Medical Application of Research. Guidelines for the Planning and Management of Consensus Development Conferences. Washington, US Government Printing Office, 1995.

3 Tobin MJ. Role and interpretation of weaning predictors. As presented at the 5th International Consensus Conference in Intensive Care Medicine: Weaning from Mechanical Ventilation. Hosted by ERS, ATS, ESICM, SCCM and SRLF; Budapest, April 28-29, 2005. Available at www.ersnet.org/ers/lr/browse/default.aspx?id=2814.

4 Esteban A, Alia I, Ibanez J, Benito S, Tobin MJ. Modes of mechanical ventilation and weaning. A national survey of Spanish hospitals. The Spanish Lung Failure Collaborative Group. Chest 1994; 106: 1188-1193.

5 Ely EW, Baker AM, Dunagan DP, et al. Effect on the duration of mechanical ventilation of identifying patients capable of breathing spontaneously. N Engl J Med 1996; 335: 1864-1869.

6 Kollef $\mathrm{MH}$, Shapiro SD, Silver $\mathrm{P}$, et al. A randomized, controlled trial of protocol-directed versus physiciandirected weaning from mechanical ventilation. Crit Care Med 1997; 25: 567-574.

7 Esteban A, Anzueto A, Frutos F, et al. Mechanical Ventilation International Study Group. Characteristics and outcomes in adult patients receiving mechanical ventilation: a 28-day international study. JAMA 2002; 287: 345-355.

8 Tobin MJ. Mechanical ventilation. N Engl J Med 1994; 330: 1056-1061.

9 Cooper LM, Linde-Zwirble WT. Medicare intensive care unit use: analysis of incidence, cost, and payment. Crit Care Med 2004; 32: 2247-2253.

10 Wagner DP. Economics of prolonged mechanical ventilation. Am Rev Respir Dis 1989; 140: S14-S18.

11 Epstein SK. Decision to extubate. Intensive Care Med 2002; 28: 535-546.

12 Epstein SK, Nevins ML, Chung J. Effect of unplanned extubation on outcome of mechanical ventilation. Am J Respir Crit Care Med 2000; 161: 1912-1916. 
13 Coplin WM, Pierson DJ, Cooley KD, Newell DW, Rubenfeld GD. Implications of extubation delay in brain-injured patients meeting standard weaning criteria. Am J Respir Crit Care Med 2000; 161: 1530-1536.

14 Hall JB, Wood LD. Liberation of the patient from mechanical ventilation. JAMA 1987; 257: 1621-1628.

15 Ely EW, Baker AM, Evans GW, Haponik EF. The prognostic significance of passing a daily screen of weaning parameters. Intensive Care Med 1999; 25: 581-587.

16 Esteban A, Frutos F, Tobin MJ, et al. A comparison of four methods of weaning patients from mechanical ventilation. Spanish Lung Failure Collaborative Group. N Engl J Med 1995; 332: 345-350.

17 Vallverdu I, Calaf N, Subirana M, Net A, Benito S, Mancebo J. Clinical characteristics, respiratory functional parameters, and outcome of a two-hour T-piece trial in patients weaning from mechanical ventilation. Am J Respir Crit Care Med 1998; 158: 1855-1862.

18 Brochard L, Rauss A, Benito S, et al. Comparison of three methods of gradual withdrawal from ventilatory support during weaning from mechanical ventilation. Am J Respir Crit Care Med 1994; 150: 896-903.

19 Jubran A, Tobin MJ. Pathophysiologic basis of acute respiratory distress in patients who fail a trial of weaning from mechanical ventilation. Am J Respir Crit Care Med 1997; 155: 906-915.

20 Capdevila XMD, Perrigault P-F, Ramonatxo M, et al. Changes in breathing pattern and respiratory muscle performance parameters during difficult weaning. Critical Care Med 1998; 26: 79-87.

21 Torres A, Gatell JM, Aznar E, et al. Re-intubation increases the risk of nosocomial pneumonia in patients needing mechanical ventilation. Am J Respir Crit Care Med 1995; 152: 137-141.

22 Esteban A, Alia I, Tobin MJ, et al. Effect of spontaneous breathing trial duration on outcome of attempts to discontinue mechanical ventilation. Spanish Lung Failure Collaborative Group. Am J Respir Crit Care Med 1999; 159: 512-518.

23 Carlucci A, Richard JC, Wysocki M, Brochard L. Noninvasive versus conventional mechanical ventilation. An epidemiologic survey. Am J Respir Crit Care Med 2001; 163: 874-880.

24 Farias JA, Retta A, Alia I, et al. A comparison of two methods to perform a breathing trial before extubation in paediatric intensive care patients. Intensive Care Med 2001; 27: 1649-1654.

25 Esteban A, Alia I, Gordo F, et al. Extubation outcome after spontaneous breathing trials with T-tube or pressure support ventilation. The Spanish Lung Failure Collaborative Group. Am J Respir Crit Care Med 1997; 156: 459-465.

26 Vitacca M, Vianello A, Colombo D, et al. Comparison of two methods for weaning patients with chronic obstructive pulmonary disease requiring mechanical ventilation for more than 15 days. Am J Respir Crit Care Med 2001; 164: 225-230.

27 Ferrer M, Esqinas A, Arancibia F, et al. Noninvasive ventilation during persistent weaning failure. Am J Respir Crit Care Med 2003; 168: 70-76.
28 Brochard L. Pressure support is the preferred weaning method. As presented at the 5th International Consensus Conference in Intensive Care Medicine: Weaning from Mechanical Ventilation. Hosted by ERS, ATS, ESICM, SCCM and SRLF; Budapest, April 28-29, 2005. Available at www.ersnet.org/ers/lr/browse/default.aspx?id =2814.

29 Bouadma L, Lellouche F, Cabello B, et al. Computerdriven management of prolonged mechanical ventilation and weaning: a pilot study. Intensive Care Med 2005; 31: 1446-1450.

30 Marini J, Smith T, Lamb V. Estimation of inspiratory muscle strength in mechanically ventilated patients: The measurement of maximal inspiratory pressure. J Crit Care 1986; 1: 32-38.

31 Caruso P, Friedrich C, Denari S, Ruiz S, Deheinzelin D. The unidirectional valve is the best method to determine maximal inspiratory pressure during weaning. Chest 1999; 115: 1096-1101.

32 Leung P, Jubran A, Tobin M. comparison of assisted ventilator modes on triggering, patient effort and dyspnoea. Am J Respir Crit Care Med 1997; 155: 1940-1948.

33 Chastre J, Fagon JY. Ventilator-associated pneumonia. Am J Respir Crit Care Med 2002; 165: 867-903.

34 Nava S, Ambrosino N, Clini E, et al. Noninvasive mechanical ventilation in the weaning of patients with respiratory failure due to chronic obstructive pulmonary disease. A randomized, controlled trial. Ann Intern Med 1998; 128: 721-728.

35 American Thoracic Society. Guidelines for the management of adults with hospital-acquired, ventilator-associated, and healthcare-associated pneumonia. Am J Respir Crit Care Med 2005; 171: 388-416.

36 Salam A, Tilluckdharry L, Amoateng-Adjepong Y, Manthous CA. Neurologic status, cough, secretions and extubation outcomes. Intensive Care Med 2004; 30: 1334-1339.

37 Epstein SK, Ciubotaru RL. Independent effects of etiology of failure and time to reintubation on outcome for patients failing extubation. Am J Respir Crit Care Med 1998; 158: 489-493.

38 Straus C, Louis B, Isabey D, Lemaire F, Harf A, Brochard L. Contribution of the endotracheal tube and the upper airway to breathing workload. Am J Respir Crit Care Med 1998; 157: 23-30.

39 Lemaire F, Teboul JL, Cinotti L, et al. Acute left ventricular dysfunction during unsuccessful weaning from mechanical ventilation. Anesthesiology 1988; 69: 171-179.

40 Pinsky MR, Summer WR, Wise RA, et al. Augmentation of cardiac function by elevation of intrathoracic pressure. J Appl Physiol 1983; 54: 950-955.

41 Pinsky MR. Breathing as exercise: the cardiovascular response to weaning from mechanical ventilation. Intensive Care Med 2000; 26: 1164-1166.

42 Naughton MT, Rahman MA, Hara K, et al. Effect of continuous positive airway pressure on intrathoracic and left ventricular transmural pressure in patients with congestive heart failure. Circulation 1995; 91: 1725-1731.

43 Nava S, Carbone G, Di Battista N, et al. Noninvasive ventilation in cardiogenic pulmonary oedema: a multicentre trial. Am J Respir Crit Care Med 2003; 168: 1432-1437. 
44 Jubran A, Mathru M, Dries D, et al. Continuous recordings of mixed venous oxygen saturation during weaning from mechanical ventilation and the ramifications thereof. Am J Respir Crit Care Med 1998; 158: 1763-1769.

45 Mohsenifar Z, Hay A, Hay J, et al. Gastric intraluminal $\mathrm{pH}$ as a predictor of success or failure in weaning patients from mechanical ventilation. Ann Intern Med 1993; 119: 794-798.

46 Montgomery AB, Holle RH, Neagley SR, Pierson DJ, Schoene RB. Prediction of successful ventilator weaning using airway occlusion pressure and hypercapnic challenge. Chest 1987; 91: 496-499.

47 Kress JP, Pohlman AS, O'Connor MF, Hall JB. Daily interruption of sedative infusions in critically ill patients undergoing mechanical ventilation. N Engl J Med 2000; 342: 1471-1477.

48 Spitzer AR, Giancarlo T, Maher L, Awerbuch G, Bowles A. Neuromuscular causes of prolonged ventilator dependency. Muscle Nerve 1992; 15: 682-686.

49 De Jonghe B, Bastuji-Garin S, Sharshar T, Outin H, Brochard L. Does ICU-acquired paresis lengthen weaning from mechanical ventilation? Intensive Care Med 2004; 30: $1117-1121$.

50 Bolton CF, Gilbert JJ, Hahn AF, Sibbald WJ. Polyneuropathy in critically ill patients. I Neurol Neurosurg Psychiatry 1984; 47: 1223-1231.

51 Couturier JC, Robert D, Monier P. Polynévrites compliquant des séjours prolongés en réanimation. [Idiopathic polyneuropathy in 11 patients under prolonged intensive care.]. Lyon Med 1984; 252: 247-249.

52 Witt NJ, Zochodne DW, Bolton CF, et al. Peripheral nerve function in sepsis and multiple organ failure. Chest 1991; 99: 176-184.

53 Campellone JV, Lacomis D, Kramer DJ, et al. Acute myopathy after liver transplantation. Neurology 1998; 50: 46-53.

54 Garnacho-Montero J, Madrazo-Osuna J, GarciaGarmendia JL, et al. Critical illness polyneuropathy: risk factors and clinical consequences. A cohort study in septic patients. Intensive Care Med 2001; 27: 1288-1296.

55 Bercker S, Weber-Carstens S, Maria D, et al. Critical illness polyneuropathy and myopathy in patients with acute respiratory distress syndrome. Crit Care Med 2005; 33: 711-715.

56 De Jonghe B, Sharshar T, Lefaucheur JP, et al. Paresis acquired in the intensive care unit: a prospective multicenter study. JAMA 2002; 288: 2859-2867.

57 Kleyweg RP, van der Meche FG, Meulstee J. Treatment of Guillain-Barre syndrome with high-dose gammaglobulin. Neurology 1988; 38: 1639-1641.

58 Bednarik J, Lucas Z, Vondracek P. Critical illness polyneuropathy: the electrophysiological components of a complex entity. Intensive Care Med 2003; 29: 1505-1514.

59 Maher J, Rutledge F, Remtulla H, Parkes A, Bernardi L, Bolton CF. Neuromuscular disorders associated with failure to wean from the ventilator. Intensive Care Med 1995; 21: 737-743.

60 Zifko UA, Zipko HT, Bolton CF. Clinical and electrophysiological findings in critical illness polyneuropathy. $J$ Neurol Sci 1998; 159: 186-193.
61 Multz AS, Aldrich TK, Prezant DJ, Karpel JP, Hendler JM. Maximal inspiratory pressure is not a reliable test of inspiratory muscle strength in mechanically ventilated patients. Am Rev Respir Dis 1990; 142: 529-532.

62 Yang KL, Tobin MJ. A prospective study of indexes predicting the outcome of trials of weaning from mechanical ventilation. $N$ Engl J Med 1991; 324: 1445-1450.

63 Conti G, Montini L, Pennisi MA, et al. A prospective, blinded evaluation of indexes proposed to predict weaning from mechanical ventilation. Intensive Care Med 2004; 30: 830-836.

64 Watson AC, Hughes PD, Harris L, et al. Measurement of twitch transdiaphragmatic, esophageal, and endotracheal tube pressure with bilateral anterolateral magnetic phrenic nerve stimulation in patients in the intensive care unit. Crit Care Med 2001; 29: 1325-1331.

65 Leijten FS, Harinck-de Weerd JE, Poortvliet DC, de Weerd AW. The role of polyneuropathy in motor convalescence after prolonged mechanical ventilation. JAMA 1995; 274: 1221-1225.

66 Douglass J, Tuxen DV, Home M, et al. Myopathy in severe asthma. Am Rev Respir Dis 1992; 146: 517-519.

67 Leijten FS, De Weerd AW, Poortvliet DC, De Ridder VA, Ulrich C, Harink-De Weerd JE. Critical illness polyneuropathy in multiple organ dysfunction syndrome and weaning from the ventilator. Intensive Care Med 1996; 22: $856-861$.

68 Thiele RI, Jakob H, Hund E, et al. Critical illness polyneuropathy: a new iatrogenically induced syndrome after cardiac surgery? Eur J Cardiothorac Surg 1997; 12: 826-835.

69 Thiele RI, Jakob H, Hund E, et al. Sepsis and catecholamine support are the major risk factors for critical illness polyneuropathy after open heart surgery. Thorac Cardiovasc Surg 2000; 48: 145-150.

70 Druschky A, Herkert M, Radespiel-Troger M, et al. Critical illness polyneuropathy: clinical findings and cell culture assay of neurotoxicity assessed by a prospective study. Intensive Care Med 2001; 27: 686-693.

71 Garnacho-Montero J, Amaya-Villar R, GarcíaGarmendía J-L, Madruso-Osuna J, Ortiz-Leyba C. Effect of critical illness polyneuropathy on the withdrawal from mechanical ventilation and the length of stay in septic patients. Crit Care Med 2005; 33: 349-354.

72 Amaya-Villar R, Garnacho-Montero J, GarciaGarmendia JL, et al. Steroid-induced myopathy in patients intubated due to exacerbation of chronic obstructive pulmonary disease. Intensive Care Med 2005; 31: 157-161.

73 Fletcher SN, Kennedy DD, Ghosh IR, et al. Persistent neuromuscular and neurophysiologic abnormalities in long-term survivors of prolonged critical illness. Crit Care Med 2003; 31: 1012-1016.

74 Herridge MS, Cheung AM, Tansey CM, et al. One year outcome in survivors of the acute respiratory distress syndrome. N Engl J Med 2003; 348: 683-693.

75 Inouye SK, Bogardus ST, Charpentier PA, et al. A multicomponent intervention to prevent delirium in hospitalized older patients. N Engl J Med 1999; 340: 669-676.

76 Lin S-M, Liu C-Y, Wang C-H, et al. The impact of delirium on the survival of mechanically ventilated patients. Crit Care Med 2004; 32: 2254-2259. 
77 Ely EW, Shintani A, Truman B, et al. Delirium as a predictor of mortality in mechanically ventilated patients in the intensive care unit. JAMA 2004; 291: 1753-1762.

78 Bergbom-Engberg I, Haljamae H. Assessment of patients' experience of discomforts during respirator therapy. Crit Care Med 1989; 17: 1068-1072.

79 Pochard F, Lanore JJ, Bellier F, et al. Subjective psychological status of severely ill patients discharged from mechanical ventilation. Clin Intensive Care 1995; 6: 57-61.

80 Chlan LL. Description of anxiety levels by individual differences and clinical factors in patients receiving mechanical ventilatory support. Heart Lung 2003; 32: 275-282.

81 Smoller JW, Pollack MH, Otto MW, Rosenbaum JF, Kradin RL. Panic, anxiety, dyspnoea, and respiratory disease. Theoretical and clinical considerations. Am J Respir Crit Care Med 1996; 154: 6-17.

82 Rotondi AJ, Chelluri L, Sirio C, et al. Patients' recollections of stressful experiences while receiving prolonged mechanical ventilation in an intensive care unit. Crit Care Med 2002; 30: 746-752.

83 Cooper AB, Thomsley KS, Young GB, Slutsky AS, Stewart TE, Hanly PJ. Sleep in critically ill patients requiring mechanical ventilation. Chest 2000; 117: 809-818.

84 Parthasarathy S, Tobin MJ. Effect of ventilator mode on sleep quality in critically ill patients. Am J Respir Crit Care Med 2002; 166: 1423-1429.

85 Gabor JY, Cooper AB, Crombach SA. Contribution of the intensive care unit environment to sleep disruption in mechanically ventilated patients and healthy subjects. Am J Respir Crit Care Med 2003; 167: 708-715.

86 Misra S, Ganzini L. Delirium, depression, and anxiety. Crit Care Clin 2003; 19: 771-787.

87 Hoist JD, Banzett RB, Lohmeier HL, Hixon TJ, Brown R. Clinical ventilator adjustments that improve speech. Chest 2003; 124: 1512-1521.

88 Holliday JE, Hyers TM. The reduction of weaning time from mechanical ventilation using tidal volume and relaxation feedback. Am Rev Respir Dis 1990; 141: 1214-1220.

89 Annane D, Sebille V, Charpentier C, et al. Effect of treatment with low doses of hydrocortisone and fludrocortisone on mortality in patients with septic shock. JAMA 2002; 288: 862-871.

90 Van Den Berghe G, Wouters P, Weekers F, et al. Intensive insulin therapy in critically ill patients. N Engl J Med 2001; 345: 1359-1367.

91 O'Brien JM Jr, Welsh CH, Fish RH, Ancukiewicz M, Kramer AM. National Heart, Lung, and Blood Institute Acute Respiratory Distress Syndrome Network. Excess body weight is not independently associated with outcome in mechanically ventilated patients with acute lung injury. Ann Intern Med 2004; 140: 338-345.

92 Tremblay A, Bandi V. Impact of body mass index on outcomes following critical care. Chest 2003; 123: 1202-1207.

93 Doekel RC, Zwillic CW, Scoggin CH, M Kryger M, Weil JV. Clinical semistarvation: depression of hypoxic ventilatory response. N Engl J Med 1976; 295: 358-361.

94 Vassilakopoulos T, Petrof BF. Ventilator-induced diaphragmatic dysfunction. Am J Respir Crit Care Med 2004; 169: 336-341.
95 Sassoon CS, Caiozzo VJ, Manka A, Sieck GC. Altered diaphragm contractile properties with controlled mechanical ventialtion. J Appl Physiol 2002; 92: 2585-2595.

96 Zergeroglu MA, McKenzie MJ, Shanely RA, Van Gammeren D, DeRuisseau KC, Powers SK. Mechanical ventilation induced oxidative stress in the diaphragm. J Appl Physiol 2003; 95: 1116-1124.

97 Nathens AB, Neff MJ, Jurkovich GJ, et al. Randomised, prospective trial of antioxidant supplementation in critically ill surgical patients. Ann Surg 2002; 236: 814-822.

98 Heyland DK, Dhaliwal R, Suchner U, Berger MM. Antioxidant nutrients: a systematic review of trace elements and vitamins in the critically ill patient. Intensive Care Med 2005; 31: 327-337.

99 Hebert PC, Blajchman MA, Cook DJ, et al. Transfusion Requirements in Critical Care Investigators, Canadian Critical Care Trials Group. Do blood transfusions improve outcomes related to mechanical ventilation? Chest 2001; 119: 1850-1857.

100 Schonhofer B, Wenzel M, Geibel M, Kohler D. Blood transfusion and lung function in chronically anemic patients with severe chronic obstructive pulmonary disease. Crit Care Med 1998; 26: 1824-1828.

101 Matic I, Majeric-Kogler V. Comparison of pressure support and T-tube weaning from mechanical ventilation: randomized prospective study. Croat Med J 2004; 45: 162-166.

102 Jones DP, Byrne P, Morgan C, Fraser I, Hyland R. Positive end-expiratory pressure versus T-piece. Extubation after mechanical ventilation. Chest 1991; 100: 1655-1659.

103 Haberthur C, Mols G, Elsasser S, Bingisser R, Stocker R, Guttmann J. Extubation after breathing trials with automatic tube compensation, T-tube, or pressure support ventilation. Acta Anaesthesiol Scand 2002; 46: 973-979.

104 Mehta S, Nelson DL, Klinger JR, Buczko GB, Levy MM. Prediction of post-extubation work of breathing. Crit Care Med 2000; 28: 1341-1346.

105 Perren A, Domenighetti G, Mauri S, Genini F, Vizzardi N. Protocol-directed weaning from mechanical ventilation: clinical outcome in patients randomized for a $30-\mathrm{min}$ or 120-min trial with pressure support ventilation. Intensive Care Med 2002; 28: 1058-1063.

106 Reissmann HK, Ranieri VM, Goldberg P, Gottfried SB. Continuous positive airway pressure facilitates spontaneous breathing in weaning chronic obstructive pulmonary disease patients by improving breathing pattern and gas exchange. Intensive Care Med 2000; 26: 1764-1772.

107 Zeggwagh AA, Abouqal R, Madani N, Zekraoui A, Kerkeb O. Weaning from mechanical ventilation: a model for extubation. Intensive Care Med 1999; 25: 1077-1083.

108 Namen AM, Ely EW, Tatter SB, et al. Predictors of successful extubation in neurosurgical patients. Am J Respir Crit Care Med 2001; 163: 658-664.

109 Koh WY, Lew TW, Chin NM, Wong MF. Tracheostomy in a neuro-intensive care setting: indications and timing. Anaesth Intensive Care 1997; 25: 365-368.

110 Khamiees M, Raju P, DeGirolamo A, AmoatengAdjepong Y, Manthous CA. Predictors of extubation outcome in patients who have successfully completed a spontaneous breathing trial. Chest 2001; 120: 1262-1670. 
111 Bach JR, Saporito LR. Criteria for extubation and tracheostomy tube removal for patients with ventilatory failure. A different approach to weaning. Chest 1996; 110: 1566-1571.

112 Fisher MM, Raper RF. The "cuff-leak" test for extubation. Anaesthesia 1992; 47: 10-12.

113 Sandhu RS, Pasquale MD, Miller K, Wasser TE. Measurement of endotracheal tube cuff leak to predict postextubation stridor and need for reintubation. J Am Coll Surg 2000; 190: 682-687.

114 Jaber S, Chanques G, Matecki S, et al. Post-extubation stridor in intensive care unit patients. Risk factors evaluation and importance of the cuff-leak test. Intensive Care Med 2003; 29: 69-74.

115 DeBast Y, De Backer D, Moraine JJ, Lemaire M, Vandenborght C, Vincent JL. The cuff leak test to predict failure of tracheal extubation for laryngeal oedema. Intensive Care Med 2002; 28: 1267-1272.

116 Laghi F, Cattapan SE, Jubran A, et al. Is weaning failure caused by low-frequency fatigue of the diaphragm? Am J Respir Crit Care Med 2003; 167: 120-127.

117 Esteban A, Anzueto A, Alia I, et al. How is mechanical ventilation employed in the intensive care unit? An international utilization review. Am J Respir Crit Care Med 2000; 161: 1450-1458.

118 Betbese AJ, Perez M, Bak E, Rialp G, Mancebo J. A prospective study of unplanned endotracheal extubation in intensive care unit patients. Crit Care Med 1998; 26: 1180-1186.

119 Saura P, Blanch L, Mestre J, Valles J, Artigas A, Fernandez R. Clinical consequences of the implementation of a weaning protocol. Intensive Care Med 1996; 22: 1052-1056.

120 Horst HM, Mouro D, Hall-Jenssens RA, Pamukov N. Decrease in ventilation time with a standardized weaning process. Arch Surg 1998; 133: 483-488.

121 Henneman E, Dracup K, Ganz T, Molayeme O, Cooper C. Effect of a collaborative weaning plan on patient outcome in the critical care setting. Crit Care Med 2001; 29: 297-303.

122 Smyrnios NA, Connolly A, Wilson MM, et al. Effects of a multifaceted, multidisciplinary, hospital-wide quality improvement program on weaning from mechanical ventilation. Crit Care Med 2002; 30: 1224-1230.

123 Scheinhorn DJ, Chao DC, Stearn-Hassenpflug M, Wallace WA. Outcomes in post-ICU mechanical ventilation: a therapist-implemented weaning protocol. Chest 2001; 119: 236-242.

124 Marelich GP, Murin S, Battistella F, Inciardi J, Vierra T, Roby M. Protocol weaning of mechanical ventilation in medical and surgical patients by respiratory care practitioners and nurses: effect on weaning time and incidence of ventilator-associated pneumonia. Chest 2000; 118: 459-467.

125 Grap MJ, Strickland D, Tormey L, et al. Collaborative practice: development, implementation, and evaluation of a weaning protocol for patients receiving mechanical ventilation. Am J Crit Care 2003; 12: 454-460.

126 Tonnelier JM, Prat G, Le Gal G, et al. Impact of a nurses' protocol-directed weaning procedure on outcomes in patients undergoing mechanical ventilation for longer than 48 hours: a prospective cohort study with a matched historical control group. Crit Care 2005; 9: R83-R89.
127 Dries DJ, McGonigal MD, Malian MS, Bor BJ, Sullivan C. Protocol-driven ventilator weaning reduces use of mechanical ventilation, rate of early reintubation, and ventilatorassociated pneumonia. J Trauma 2004; 56: 943-951.

128 Randolph AG, Wypij D, Venkataraman ST, et al. Effect of mechanical ventilator weaning protocols on respiratory outcomes in infants and children: a randomized controlled trial. JAMA 2002; 288: 2561-2568.

129 Krishnan JA, Moore D, Robeson C, Rand CS, Fessler HE. A prospective, controlled trial of a protocol-based strategy to discontinue mechanical ventilation. Am J Respir Crit Care Med 2004; 169: 673-678.

130 Berenholtz SM, Milanovich S, Faircloth A, et al. Improving care for the ventilated patient. Jt Comm J Qual Saf 2004; 30: 195-204.

131 Girault C, Daudenthun I, Chevron V, Tamion F, Leroy J, Bonmarchand G. Noninvasive ventilation as a systematic extubation and weaning technique in acute-on-chronic respiratory failure. A prospective, randomized controlled study. Am J Respir Crit Care Med 1999; 160: 86-92.

132 Chen J, Qiu D, Tao D. Time for extubation and sequential noninvasive mechanical ventilation in COPD patients with exacerbated respiratory failure who receive invasive ventilation. Zhonghua Jie He He Hu Xi Za Zhi 2001; 24: 99-100.

133 Bohner H, Kindgen-Milles D, Grust A, et al. Prophylactic nasal continuous positive airway pressure after major vascular surgery: results of a prospective randomized trial. Langenbecks Arch Surg 2002; 387: 21-26.

134 Squadrone V, Coha M, Cerutti E, et al. Piedmont Intensive Care Units Network (PICUN). Continuous positive airway pressure for treatment of postoperative hypoxemia: a randomized controlled trial. JAMA 2005; 293: 589-595.

135 Kilger E, Briegel J, Haller M, et al. Effects of noninvasive positive pressure ventilatory support in non-COPD patients with acute respiratory insufficiency after early extubation. Intensive Care Med 1999; 25: 1374-1380.

136 Antonelli M, Conti G, Bufi M, et al. Noninvasive ventilation for treatment of acute respiratory failure in patients undergoing solid organ transplantation: a randomized trial. JAMA 2000; 283: 235-241.

137 Keenan SP, Powers C, McCormack DG, Block G. Noninvasive positive-pressure ventilation for postextubation respiratory distress: a randomized controlled trial. JAMA 2002; 287: 3238-3244.

138 Esteban A, Frutos-Vivar F, Ferguson ND, et al. Noninvasive positive-pressure ventilation for respiratory failure after extubation. N Engl J Med 2004; 350: 2452-2460.

139 Jardin F, Farcot JC, Boisante L, et al. Influence of positive end-expiratory pressure on left ventricular performance. N Engl J Med 1981; 304: 387-392.

140 Petrof BJ, Legare M, Goldberg P, Milic-Emili J, Gottfried SB. Continuous positive airway pressure reduces work of breathing and dyspnoea during weaning from mechanical ventilation in severe chronic obstructive pulmonary disease. Am Rev Respir Dis 1990; 141: 281-289.

141 Feeley TW, Saumarez R, Klick JM, McNabb TG, Skillman JJ. Positive end-expiratory pressure in weaning patients from controlled ventilation. A prospective randomised trial. Lancet 1975; 2: 725-729.

142 Bailey CR, Jones RM, Kelleher AA. The role of continuous positive airway pressure during weaning from mechan- 
ical ventilation in cardiac surgical patients. Anaesthesia 1995; 50: 677-681.

143 Appendini L, Purro A, Gudjonsdottir M, et al. Response of ventilator-dependent patients with chronic obstructive pulmonary disease to proportional assist ventilation and continuous positive airway pressure. Am J Respir Crit Care Med 1999; 159: 1510-1517.

144 Gay PC, Hess DR, Hill NS. Noninvasive proportional assist ventilation for acute respiratory insufficiency. Comparison with pressure support ventilation. Am J Respir Crit Care Med 2001; 164: 1606-1611.

145 Delaere S, Roeseler J, D'hoore W, et al. Respiratory muscle workload in intubated, spontaneously breathing patients without COPD: pressure support versus proportional assist ventilation. Intensive Care Med 2003; 29: 949-954.

146 Tassaux D, Dalmas E, Gratadour P, Jolliet P. Patientventilator interactions during partial ventilatory support: a preliminary study comparing the effects of adaptive support ventilation with synchronized intermittent mandatory ventilation plus inspiratory pressure support. Crit Care Med 2002; 30: 801-807.

147 Lourens MS, van den Berg B, Aerts JG, Verbraak AF, Hoogsteden HC, Bogaard JM. Expiratory time constants in mechanically ventilated patients with and without COPD. Intensive Care Med 2000; 26: 1612-1618.

148 Cassina T, Chiolero R, Mauri R, Revelly JP. Clinical experience with adaptive support ventilation for fasttrack cardiac surgery. J Cardiothorac Vasc Anesth 2003; 17: 571-575.

149 Petter AH, Chiolero RL, Cassina T, Chassot PG, Muller XM, Revelly JP. Automatic "respirator/weaning" with adaptive support ventilation: the effect on duration of endotracheal intubation and patient management. Anesth Analg 2003; 97: 1743-1750.

150 Sulzer CF, Chiolero R, Chassot PG, Mueller XM, Revelly JP. Adaptive support ventilation for fast tracheal extubation after cardiac surgery: a randomized controlled study. Anesthesiology 2001; 95: 1339-1345.

151 Dojat M, Brochard L, Lemaire F, Harf A. A knowledge based system for assisted ventilation of patients in intensive care units. Int J Clin Monit Comput 1992; 9: 239-250.

152 Dojat M, Harf A, Touchard D, Laforest M, Lemaire F, Brochard L. Evaluation of a knowledge-based system providing ventilatory management and decision for extubation. Am J Respir Crit Care Med 1996; 153: 997-1004.

153 Dojat M, Harf A, Touchard D, Lemaire F, Brochard L. Clinical evaluation of a computer-controlled pressure support mode. Am J Respir Crit Care Med 2000; 161: 1161-1166.

154 Cohen IL, Booth FV. Cost containment and mechanical ventilation in the United States. New Horizons 1994; 2: 283-290.

155 Seneff MG, Zimmerman JE, Knaus WA, Wagner DP, Draper EA. Predicting the duration of mechanical ventilation. The importance of disease and patient characteristics. Chest 1996; 110: 469-479.

156 Kurek CJ, Cohen IL, Lambrinos J, Minatoya K, Booth FV, Chalfin DB. Clinical and economic outcome of patients undergoing tracheostomy for prolonged mechanical ventilation in New York state during 1993: analysis of
6,353 cases under diagnosis-related group 483. Crit Care Med 1997; 25: 983-988.

157 Pilcher DV, Bailey MJ, Treacher DF, Hamid S, Williams AJ, Davidson AC. Outcomes, cost and long term survival of patients referred to a regional weaning centre. Thorax 2005; 60: 187-190.

158 Cox CE, Carson SS, Holmes GM, Howard ABS, Carey TS. Increase in tracheostomy for prolonged mechanical ventilation in North Carolina, 1993-2002. Crit Care Med 2004; 32: 2219-2226.

159 Simpson TP, Day CJ, Jewkes CF, Manara AR. The impact of percutaneous tracheostomy on intensive care unit practice and training. Anaesthesia 1999; 54: 186.

160 Stauffer JL, Olson DE, Petty TL. Complications and consequences of endotracheal intubation and tracheotomy. A prospective study of 150 critically ill adult patients. Am J Med 1981; 70: 65-76.

161 Kress JP, Gehlbach B, Lacy M, Pliskin N, Pohlman AS, Hall JB. The long-term psychological effects of daily sedative interruption on critically ill patients. Am J Respir Crit Care Med 2003; 168: 1457-1461.

162 Astrachan DI, Kirchner JC, Goodwin WJ Jr. Prolonged intubation versus tracheotomy: complications, practical and psychological considerations. Laryngoscope 1988; 98: 1165-1169.

163 L'Her E, Lellouche F, Ferrand E, Prat G, Brochard L. Is tracheostomy less comfortable than translaryngeal intubation? Am J Respir Crit Care Med 2003; 167: A302.

164 Diehl J-L, El Atrous S, Touchard D, Lemaire F, Brochard L. Changes in the work of breathing induced by tracheotomy in ventilator-dependent patients. Am J Respir Crit Care Med 1999; 159: 383-388.

165 Davis K Jr, Campbell RS, Johannigman JA, Valente JF, Branson RD. Changes in respiratory mechanics after tracheostomy. Arch Surg 1999; 134: 59-62.

166 Dunham CM, LaMonica C. Prolonged tracheal intubation in the trauma patient. J Trauma 1984; 24: 120-124.

167 Rodriguez JL, Steinberg SM, Luchetti FA, Gibbons KJ, Taheri PA, Flint LM. Early tracheostomy for primary airway management in the surgical critical care setting. Surgery 1990; 108: 655-659.

168 Sugerman HJ, Wolfe L, Pasquale MD, et al. Multicenter, randomized, prospective trial of early tracheostomy. J Trauma 1997; 43: 741-747.

169 Rumbak MJ, Newton M, Truncale T, Schwartz SW, Adams JW, Hazard PB. A prospective, randomized, study comparing early percutaneous dilational tracheotomy to prolonged translaryngeal intubation (delayed tracheotomy) in critically ill medical patients. Crit Care Med 2004; 32: 1689-1694. Erratum in Crit Care Med 2004; 32: 2566.

170 Jacobs S, Al Rasheed AM, Abdulsamat W, et al. Effects of a simple protocol on infective complications in intensive care unit patients undergoing percutaneous dilatational tracheostomy. Respir Care 2003; 48: 29-37.

171 Rello J, Lorente C, Diaz E, et al. Incidence, etiology, and outcome of nosocomial pneumonia in ICU patients requiring percutaneous tracheotomy for mechanical ventilation. Chest 2003; 124: 2239-2243.

172 Bouderka MA, Fakhir B, Bouaggad A, Hmamouchi B, Hamoudi D, Harti A. Early tracheostomy versus pro- 
longed endotracheal intubation in severe head injury. $J$ Trauma 2004; 57: 251-254.

173 Saffle JR, Morris SE, Edelman L. Early tracheostomy does not improve outcome in burns patients. J Burn Care Rehabil 2002; 23: 431-438.

174 Teoh WH, Goh KY, Chan C. The role of early tracheostomy in critically ill neurosurgical patients. Ann Acad Med Singapore 2001; 30: 234-238.

175 Brook AD, Sherman G, Malen J, Kollef MH. Early versus late tracheostomy in patients who require mechanical ventilation. Am J Crit Care 2000; 9: 352-359.

176 Maziak DE, Meade MO, Todd TR. The timing of tracheotomy: a systematic review. Chest 1998; 114: 605-609.

177 Armstrong PA, McCarthy MC, Peoples JB. Reduced use of resources by early tracheostomy in ventilator-dependent patients with blunt trauma. Surgery 1998; 124: 763-766.

178 Blot F, Guiguet M, Antoun S, Leclercq B, Nitenberg G, Escudier B. Early tracheotomy in neutropenic, mechanically ventilated patients: rationale and results of a pilot study. Support Care Cancer 1995; 3: 291-296.

179 D'Amelio LF, Hammond JS, Spain DA, Sutyak JP. Tracheostomy and percutaneous endoscopic gastrostomy in the management of the head-injured trauma patient. Am Surg 1994; 60: 180-185.

180 Lesnik I, Rappaport W, Fulginiti J, Witzke D. The role of early tracheostomy in blunt, multiple organ trauma. Am Surg 1992; 58: 346-349.

181 El-Naggar $M$, Sadagopan S, Levine $H$, Kantor $H$, Collins VJ. Factors influencing choice between tracheostomy and prolonged translaryngeal intubation in acute respiratory failure: a prospective study. Anesth Analg 1976; 55: 195-201.

182 Heffner JE, Zamora CA. Clinical predictors of prolonged translaryngeal intubation in patients with the adult respiratory distress syndrome. Chest 1990; 97: 447-452.

183 Troche G, Moine $P$. Is the duration of mechanical ventilation predictable? Chest 1997; 112: 745-751.

184 Sellers BJ, Davis BL, Larkin PW, Morris SE, Saffle JR. Early prediction of prolonged ventilator dependence in thermally injured patients. J Trauma 1997; 43: 899-903.

185 Kollef MH, Ahrens TS, Shannon W. Clinical predictors and outcomes for patients requiring tracheostomy in the intensive care unit. Crit Care Med 1999; 27: 1714-1720.

186 Engoren M, Arslaninan-Engoren C, Fenn-Buderer N. Hospital and long-term outcome after tracheostomy for respiratory failure. Chest 2004; 125: 220-227.

187 LoCicero J, McCann B, Massad M, Joob AW. Prolonged ventilatory support after open-heart surgery. Crit Care Med 1992; 20: 990-992.

188 Frutos-Vivar F, Esteban A, Apezteguia C, et al. Outcome of mechanically ventilated patients who require a tracheostomy. Crit Care Med 2005; 33: 290-298.

189 Freeman BD, Isabella K, Lin N, Buchman TG. A metaanalysis of prospective trials comparing percutaneous and surgical tracheostomy in critically ill patients. Chest 2000; 118; 1412-1418.

190 Freeman BD, Isabella K, Cobb JP, et al. A prospective, randomized study comparing percutaneous with surgical tracheostomy in critically ill patients. Crit Care Med 2001; 29: 926-930.
191 Nelson JE, Meier DE, Litke A, Natale DA, Siegel RE, Morrison RS. The symptom burden of chronic critical illness. Crit Care Med 2004; 32: 1527-1534.

192 Azoulay E, Pochard F, Kentish-Barnes N, et al. Risk of post-traumatic stress symptoms in family members of intensive care unit patients. Am J Respir Crit Care Med 2005; 171: 987-994.

193 Jones C, Skirrow P, Griffiths RD, et al. Rehabilitation after critical illness: a randomized, controlled trial. Crit Care Med 2003; 31: 2456-2461.

194 Rudy EB, Daly BJ, Douglas S, Montenegro HD, Song R, Dyer MA. Patient outcome for the chronically critically ill: special care unit versus intensive care unit. Nurs Res 1995; 44: 324-331.

195 Seneff MG, Wagner D, Thompson D, Honeycutt C, Silver MR. The impact of long-term acute-care facilities on the outcome and cost of care for patients undergoing prolonged mechanical ventilation. Crit Care Med 2000; 28: 342-350.

196 Elpern EH, Larson R, Douglass P, et al. Long-term outcomes for elderly survivors of prolonged ventilator assistance. Chest 1989; 96: 1120-1124.

197 Robson V, Poynter J, Lawler PG, et al. The need for a regional weaning centre, a one-year survey of intensive care weaning delay in the Northern region of England. Anaesthesia 2003; 58: 161-165.

198 Gracey DR, Hardy D, Naessens JM, Silverstein MD, Hubmayr RD. The Mayo Ventilator-Dependent Rehabilitation Unit: a 5-year experience. Mayo Clin Proc 1997; 72: 13-19.

199 Carson SS, Bach PB, Brzozowski L, et al. Outcomes after long-term acute care. An analysis of 133 mechanically ventilated patients. Am J Respir Crit Care Med 1999; 159: 1568-1573.

200 De Vivo MJ, Ivie CS. Life expectancy of ventilator dependent persons with spinal cord injuries. Chest 1995; 108: 226-232.

201 Schönhofer B, Euteneuer S, Nava S, Suchi S, Kohler D. Survival of mechanically ventilated patients admitted to a specialised weaning centre. Intensive Care Med 2002; 28: 908-916.

202 Bagley PH, Cooney E. A community-based regional ventilator weaning unit. Chest 1997; 111: 1024-1029.

203 Gracey DR, Hardy DC, Koenig GE. The chronic ventilator-dependent unit: a lower-cost alternative to intensive unit care. Mayo Clin Proc 2000; 75: 445-449.

204 Douglas SL, Daly BJ, Gordon N, Brennan PF. Survival and quality of life: short-term versus long-term ventilator patients. Crit Care Med 2002; 30: 2655-2662.

205 Medicare Payment Advisory Commission. Defining longterm care hospitals. Chapter 5; June 2004 report. www.medpac.gov/publications. Date last accessed November 2004.

206 Latriano B, McCauley P, Astiz ME, Greenbaum D, Rackow EC. Non-ICU care of hemodynamically stable mechanically ventilated patients. Chest 1996; 109: 1591-1596.

207 Scheinhorn DJ, Chao DC, Stearn-Hassenpflug M, LaBree LD, Heltsley DJ. Post-ICU mechanical ventilation: treatment of 1,123 patients at a regional weaning center. Chest 1997; 111: 1654-1659.

208 Dasgupta A, Rice R, Mascha E, et al. Four-year experience with a unit for long-term ventilation (respiratory special 
care unit) at the Cleveland Clinic Foundation. Chest 1999; 116: 447-455.

209 Gracey DR, Viggiano RW, Naessens JM, Hubmayr RD, Silverstein MD, Koenig GE. Outcomes of patients admitted to a chronic ventilator-dependent unit in an acute-care hospital. Mayo Clin Proc 1992; 67: 131-136.

210 Chatila W, Kreimer DT, Criner GJ. Quality of life in survivors of prolonged mechanical ventilatory support. Crit Care Med 2001; 29: 737-742.

211 Ambrosino N, Bruletti G, Scala V, Porta R, Vitacca M. Cognitive and perceived health status in patient with chronic obstructive pulmonary disease surviving acute on chronic respiratory failure: a controlled study. Intensive Care Med 2002; 28: 170-177.

212 Chelluri L, Im MPH, Kyung AMS, Belle SH. Long-term mortality and quality of life after prolonged mechanical ventilation. Crit Care Med 2004; 32: 61-69.

213 Pehrsson K, Olofson J, Larsson S, Sullivan M. Quality of life of patients treated by home mechanical ventilation due to restrictive ventilatory disorders. Respir Med 1994; 88: 21-26.

214 Janssens JP, Penalosa B, Degive C, Rabeus M, Rochat T. Quality of life of patients under home mechanical ventilation for restrictive lung diseases: a comparative evaluation with COPD patients. Monaldi Arch Chest Dis 1996; 51: 178-184.

215 Markstrom A, Sundell K, Lysdahl M, Andersson G, Schedin U, Klang B. Quality-of-life evaluation of patients with neuromuscular and skeletal diseases treated with noninvasive and invasive home mechanical ventilation. Chest 2002; 122: 1695-1700.

216 Windisch W, Freidel K, Schucher B, et al. Evaluation of health-related quality of life using the MOS 36-Item Short-Form Health Status Survey in patients receiving noninvasive positive pressure ventilation. Intensive Care Med 2003; 29: 615-621.

217 Windisch W, Freidel K, Schucher B, et al. The severe respiratory insufficiency (SRI) questionnaire: a specific measure of health-related quality of life in patients receiving home mechanical ventilation. J Clin Epidemiol 2003; 56: 752-759.
218 Murphy DJ, Burrows D, Santilli S, et al. The influence of the probability of survival on patients' preferences regarding cardiopulmonary resuscitation. $N$ Engl J Med 1994; 330: 545-549.

219 Curtis JR, Bennett CL, Horner RD, Rubenfeld GD, DeHovitz JA, Weinstein RA. Variations in intensive care unit utilization for patients with human immunodeficiency virus-related Pneumocystis carinii pneumonia: importance of hospital characteristics and geographic location. Crit Care Med 1998; 26: 668-675.

220 Sprung CL, Cohen SL, Sjokvist P. End-of-life practices in European Intensive Care Units: the Ethicus Study. JAMA 2003; 290: 790-797.

221 Azoulay E, Chevret S, Leleu G, et al. Half the families of intensive care unit patients experience inadequate communication with physicians. Crit Care Med 2000; 28: 3044-3049.

222 Prendergast TJ, Luce JM. Increasing incidence of withholding and withdrawal of life support from the critically ill. Am J Respir Crit Care Med 1997; 155: 15-20.

223 Dowdy MD, Robertson C, Bander JA. A study of proactive ethics consultation for critically and terminally ill patients with extended lengths of stay. Crit Care Med 1998; 26: 252-259.

224 Campbell SG, Marrie TJ, Anstey R, Dickinson G, Ackroyd-Stolarz S. The contribution of blood cultures to the clinical management of adult patients admitted to the hospital with community-acquired pneumonia: a prospective observational study. Chest 2003; 123 1142-1150.

225 Schneiderman LJ, Gilmer T, Teetzel HD, et al. Effect of ethics consultations on nonbeneficial life-sustaining treatments in the intensive care setting: a randomized controlled trial. JAMA 2003; 290: 1166-1172.

226 Crawley LM, Marshall PA, Lo B, Koenig BA. End-of-Life Care Consensus Panel. Strategies for culturally effective end-of-life care. Ann Intern Med 2002; 136: 673-679.

227 Treece PD, Engelberg RA, Crowley L, et al. Evaluation of a standardized order form for the withdrawal of life support in the intensive care unit. Crit Care Med 2004; 32: 1141-1148. 